\title{
THE BATTLE OF KADESH: THE CHARIOT FRIEZE AT ABYDOS
}

By Anthony Spalinger

The Abydos reliefs of the battle of Kadesh have yet to be published in exemplary form by Egyptologists. Notwithstanding the useful plates in the second volume of Wreszinski's monumental Atlas, and the earlier detailed line drawings of Edouard Naville, this battle presentation remains unanalyzed from an art historical viewpoint. ${ }^{1}$ The latter statement may first appear to be overly critical, especially in light of the recent studies of Marcus Müller and Susanna Heinz, both of whom have devoted much attention to the New Kingdom depictions of war. Nonetheless, a detailed study concentrated upon one self-contained series of pictorial reliefs has much to offer, especially when we exclude the other exemplars from the Ramesseum, Karnak, Luxor, and Abu Simbel. In this light it is interesting that Naville, who was the first to understand the historical progression of the Abydene representations, was also the first to pay attention to the "beauty of the hieroglyphic signs" of the Poem that concludes the entire representation. ${ }^{2}$

The scenes commence on the west or rear wall of Ramesses II's temple at Abydos. This entire wall is occupied with Phase I of the Kadesh battle in which the $\mathrm{Na}^{\mathrm{C}}$ arn troops are seen marching to the

1 There is a useful summary of these reliefs and the others (Abu Simbel, Ramesseum, Luxor, and Karnak) in G. A. GABALlA, Narrative in Egyptian Art, Mainz am Rhein 1975, 113-19. The standard editions of the scenes are: W. WRESZINSKI, Atlas zur altägyptischen Kulturgeschichte II, Leipzig, 1935, pls. 16-24; ChARLEs KuentZ, La bataille de Qadech, Cairo 1928-34, pls. XVII-XXIII; and E. NAVILLE, Détails relevés dans les ruines de quelques temples égyptiens, Paris 1930, pls. V-XXII (his drawings are sometimes inaccurate in fine details). In addition, I have consulted my detailed photographs made in 1982.

Recently, there have been detailed studies of the war scenes of the New Kingdom: M. MülLer, Die Thematik der Schlachtenreliefs, MA Dissertation, Tübingen 1985, 79-80 in particular, and his most recent work, Der König als Feldherr, PhD. Dissertation, Tübingen, 2001; and SusAnNA Constanze Heinz, Die Feldzugsdarstellungen des Neuen Reiches, Vienna 2001. The reader should consult their detailed analyses as both of the authors' works complement this presentation, and I will refer to them only where my specific details correspond to their work. left (north) against which the now lost camp scene was carved. The manner of carving is unique among the Kadesh depictions. ${ }^{3}$ Sunken relief was employed, as we have come to expect, but the details are far better rendered than in the reliefs of the other temples. The intricate internal carvings of the hieroglyphs of the Poem parallel this. They too are well sculpted, rendered also "Classical" in their layout and structure. For example, the nearby Dedicatory Inscription of Ramesses II on the portico of Seti's temple presents a poor showing in comparison to the Kadesh Poem at Abydos insofar as the former shows a more schematic outlook, perhaps rapidly executed as well. ${ }^{4}$

At Abydos, the divisions of the "phases" are more solidly presented. The three portions of the battle are well separated from each other, and even though much of the scenes has been lost owing to time, the static quality of what remains cannot be overlooked. ${ }^{5}$ Indeed, as only the lowest portions of the walls remain, we are faced with the inherent bias of not being able to examine the actual battlefield encounter between the Egyptians and the Hittites. Notwithstanding this situation, the presentation at

Most recently, see the short analysis on the Abydos temple of Ramesses II by Mansour EL-Noubi, ArOr 67 (1999) 21-44. One awaits the final publication of K. P. Kuhlmann.

${ }^{2}$ Naville, Détails relevés, 23 (pls. XXIII-XXV). They may be seen in photographs on pls. I-V of KuENTZ's work; pl. VI presents facsimiles of certain hieroglyphic signs.

${ }^{3}$ I will follow the standard analysis first drawn up in exemplary fashion by KENNETH A. KITCHEN: KRI II 125-8.

4 As I am at present engaged in a study of the Dedicatory Inscription, I shall leave my comments here to a minimum. The old edition of Auguste Mariette, Abydos. Descriptions des fouilles exercutées sur l'emplacement de la ville I, Paris 1869, pls. 5-9 is somewhat useful. Nonetheless, I must thank Prof. John Baines of Oxford University for allowing me to obtain a series of excellent photographic reproductions of this key hieroglyphic text.

5 As is well known, virtually all of the upper rows of stones have been lost. In fact, some portions of the two walls recorded by Naville are not to be found on Wreszinski's photographs. 
Abydos reveals a more static, regular and structured set-up than any of the other representations. ${ }^{6}$

I believe that this aspect is partly to be explained by the use of the blank wall space available to the artists. Both the west wall and the north wall were employed for the Kadesh conflict. Phase II commences exactly at the extreme right hand side of the north wall, right next to the cornice. There, we see the battle itself, or to be more precise, what is left of it. The third act (Presentation) is located about twothirds farther on with a doorway effectively forming the end. To the left the opening portion of the Poem can be found. The entire system of layout parallels that of Ramesses III at Medinet Habu. ${ }^{7}$ There, the rear or west wall was occupied by three so-called "fictive" battle scenes located in Nubia (south side). Then come three scenes devoted to the commencement of the First Libyan war of year 5. Turning the corner, three more reliefs cover the same encounter. Following them is the Sea Peoples' encounter of year 8. Six scenes, neatly divided by a royal line hunt exactly in the middle, complete this series of depictions as the campaign concludes at the second pylon. Finally, moving forward to the east we reach the Second Libyan War, the final conflict of the king. There, the representations run around to the western or rear portion of the first pylon. The southern wall is mainly devoted to the calendar. A similar arrangement can be seen at Luxor if only because the blank walls at the west, located between the colonnade of Tutankhamun and that of Amunhotep III, were also filled with the Kadesh scenes.

On the south wall at Abydos will be found the temple calendar. Here, as at Medinet Habu (and the Ramesseum) the progression is from the rear to the front. In the middle of the lengthy decree there is a major speech of the goddess Seshat to the king. ${ }^{8}$ As Kitchen pointed out, this was an adaptation of a religious text that was first carved, so far as we know, in the Stairway Corridor of Seti I's temple at Abydos.
There, the male deity Thoth presides and speaks. Despite this "intervention" it is readily discernable that the arrangement of the wars at Ramesses II's Abydene temple can be compared effectively with only those at Medinet Habu, with the Ramesseum standing aside, mainly owing to its very poor condition (Note, however, that on the south wall there was the expected calendar).

In other words, owing to the architectural layout of Abydos, its early date in the reign of Ramesses II, and the free use of blank space, this temple parallels the mortuary edifice of Ramesses III, with, of course, revealing many differences in scenic presentation. The great complex at Karnak as well as the temple of Luxor provide no useful comparison. At best, a table of contrasts can be made. These buildings were not begun under the first years of a monarch or the final ones of a preceding Pharaoh. Their design, as well, did not follow the standardized setup of mortuary temples to the west, and we must remember that Seti I's as well as Ramesses II's edifices at Abydos were $H w t$ 's, exactly as those funerary complexes on the left bank at Thebes. ${ }^{9}$

Last but not least, Abu Simbel with its compressed arrangement (owing to space) as well as the absence of the Poem can be brought into the discussion. ${ }^{10}$ The entire interior northern wall of Room $\mathrm{F}$ is devoted to the battle. Two registers divide the phases of the conflict: Phase I occupies the lowest one whereas Phases II and III are carved above. (One moves from the front to the rear, or to be more precise, II is located to the left or west whereas I is to the right or east.) A few portions of the less important Phase IV will be found in the same chamber on the west wall. Nonetheless, as has been remarked on another occasion, at Abu Simbel space reasons in conjunction to using only interior walls forced an adaptation of the standard arrangement of the battle of Kadesh. Yet, and this point cannot be overlooked, the structure of the battle, especially Phase I, bears a

6 This situation was adumbrated in my chapter "Notes on the Reliefs of the Battle of Kadesh", in: H. GoEdicke (ed.), Perspectives on The Battle of Kadesh, Baltimore, $1985,1-42$. I am also indebted to the useful comments of the late William Murnane, who discussed this issue with me in Los Angeles in 1999 when we covered the textual tradition of the Kadesh inscriptions.

7 In general, see W. WIDMER, ZÄS 102 (1975), 67-77 and B. Cifola, Or 57 (1988), 275-306, and Or 60 (1991), 9-57.

8 Kitchen, Ramesside Inscriptions I, Notes and Comments, Oxford-Cambridge MA, 1993 126-7.

9 The entire situation is explained in G. HAENy's study, The New Kingdom 'Mortuary Temples' and 'Mansions of Millions of Years', in: B. E. SHAFER (ed.), Temples of Ancient Egypt, London-New York 1998, 111-13. For the latest analysis of such temples, see B. J. J. Haring, Divine Households, Leiden, 1997 23-6.

10 For Abu Simbel, I shall rely upon Centre de Documentation et d'Études sur l'Ancien Égypte, Grand temple d'Abou Simbel. La bataille de Qadech, Cairo 1971, and especially pl. IV. 
close similarity to that at Abydos, and we shall return to this aspect later in the discussion.

\section{I.}

The march of the $\mathrm{Na}^{\mathrm{c}}$ arn commences at the extreme southwest of the exterior western wall at Abydos. As Gardiner observed, Abu Simbel is the most complete and contains some explicit statements of fact absent elsewhere, but does not have the Poem. ${ }^{11}$ But the fact that the artists under direction of Pharaoh included these men in the first phase of the battle indicates their importance rather than, as earlier Egyptologists believed, that they were downplayed in the account. True, the Poem does not mention them, but the pictorial representations do, and we moderns who attempt to reconstruct the thought processes of Ramesses cannot overlook this point. The $\mathrm{Na}^{\mathrm{c}}$ arn and their crucial role in supporting the king when the Hittite chariots suddenly attacked his camp is a given fact of the visual report.

At Abydos the rows of marching men are flanked at the rear and at the bottom by their companions with chariots. ${ }^{12}$ The arrangement is as follows: two men on chariot are preceded by four footsoldiers. The man on the right of the chariot holds the shield in his left hand. Therefore, we see the face of the shield, frontally of course, the handhold or grip being located away from our eyes. ${ }^{13}$ The horses are set up in an interesting fashion, one that is connected to the use of the reins held by the charioteer who is placed to the left on the chariot platform. Let us begin with the first chariot and use that small design as a working paradigm (Figs. 1-3).

The horses' heads are at an acute angle to the horizontal. That is to say, they are shown being pulled backwards by the force of the reins held in the right hand of the charioteer. All of the horses' legs at this point form a simple design; i.e., they only switch when we reach the battle encounter. But at the beginning of the scene the legs are different from those of the following two equids. Here is the system:

First Chariot: The left horse (first to be seen) has one upward moving left leg which is off the ground. The rear leg (left) is set on the ground in a temporarily quiescent position. The right legs are opposed: the front one is retracted (typical for quadrupedal movement) and the rear one is the further behind. In other words the common set-up is depicted. The right horse (rear to the viewer) parallels the first. The left hand hangs down at the side of the man's body. The front right leg is on the ground; the front left leg is in the air. The rear left leg is thus forward whereas the rear right is back. Four men in groups of two apiece walk next to the chariot at the rear. None of them (and those later depicted) have weapons or shields. One final point: the reins have not been completely carved. ${ }^{14}$

The system of cheekstraps on the horses always follow the "dual" principal, although it is difficult from this group to ascertain whether the rein system worked through the "Nasenbandzaum" system or the "Trensenzaum" one. ${ }^{15}$ Relying solely upon

11 Sir A. GARDINER, The Kadesh Inscriptions of Ramesses II, Oxford 1960, 3.

12 The specific details of the chariots, horses, and warriors will be covered below. For the moment, let me single out the following useful discussion of the military preparedness of the Egyptians and their foes: M. A. LITtauer-J. H. Crounel, Wheeled Vehicles and Ridden Animals in the Ancient Near East, Leiden-Cologne 1979; Anja Herold, Streitwagentechnologie in der Ramses-Stadt, Mainz 1999; and U. Hofmann, Furhwesen und Pferdehaltung im alten Ägypten, Bonn 1989. There is a review of HeINZ by me in JAOS 122 (2002), 125-7. A brief analysis of horse depictions in the New Kingdom will be found by H. A. LIEBOWITZ, JARCE 6 (1967), 129-34.

For the Hittites, see now the detailed analysis of R. H. BEAL, The Organisation of the Hittite Military, Heidelberg 1992, to which I am very indebted. Add as well E. B. Pusch, 'Pi-Ramesses-Beloved-of-Amun, Headquarters of thy Chariotry'. Egyptians and Hittites in the Delta residence of the Ramessides, in: A. EGGEBRECHT (ed.), Pelizaeus-Museum Hildesheim Guidebook. The Egyptian Collection, Mainz 1996, 126-44.

13 This is not always the case: see my comments later on in this discussion with regard to the Abu Simbel scene. Later on I shall cover the situation of direction (facing right or left), and its importance in ascertaining the artistic conventions of the Egyptians.

14 They should run up to the cheekpiece: see the useful diagram in LitTAuer-Crouwel, Chariots and Related Equipment from the Tomb of Tut'ankhamun, Oxford 1985, fig. 2. All the terminology related to horses and chariots may be found in the introduction of these two authors to their work, Wheeled Vehicles, Chapter 2. See as well A. Herold, Streitwagentechnologie, XXI-XXVI and 8-10; and LitTauer, Antiquity 43 (1969), 289-300, Antiquity 48 (1974), 293-5.

15 Herold, Streitwagentechnologie, 133-6; see as well the earlier discussion of LitTAuer-Crouwel, Wheeled Vehicles, 89-90. Cheekpieces with three straps are extremely rare in Egypt. The known examples refer only to the Pharaoh: Thutmose IV and Tutankhamun. Conveniently, see pls. 67-8 in Herold's work. HoFMANN's work cited in note 12 above is useful to read in this context. Nevertheless, it is now somewhat dated. Herold (p. 134) 
the Abydos representation, I believe it to be the case that with these two cheekstraps, the latter method of control was practiced. Note as well that the discoid cheekpiece instead of the flat rectangular one is present. ${ }^{16}$

Second Chariot: The front left legs of the horses are on the ground; the front right legs are in the air. This is pattern B. The rear left legs are, as expected, to the back and the rear right ones to the front. On the other hand, the reins are held differently. The right hand of the charioteer pulls the reins at an angle not as sharp as his first companion. The reins have not been completely carved here as well. ${ }^{17}$ In addition, there is a neat loop that moves into the left hand, thereby indicating that the cord is not held as taught as in the first case. ${ }^{18}$ This portion of the reins enters the charioteer's hand, and it is there that the second portion is held. Four men again march to the right of the chariot.

The artists have thus rendered two separate means of chariot locomotion. At the rear the charioteer has an easier way with his animals whereas in front of him the man appears to be controlling his horses in a more deliberate fashion. Now it is correct that such alternations can be found in many more pictorial representations from Ancient Egypt. The issue here, however, is more complicated than establishing a simple rule of alternation, whether it be A-B, A-B, and so forth, or even A-B-C, etc. The exacting specificity of design bears deeper analysis. Indeed, it may be subsumed under the rubric of "playing with narrative", a focus of artistic intent that Leo Bersani and Ulysse Dutoit have examined in detail. ${ }^{19}$ For the moment, let me turn to their discussion of these apparent accidental similarities.

refers to a useful example from Amarna (J. D. CoONEY, Amarna Reliefs from Hermopolis in American Collections, Brooklyn 1965, 52-4, No. 30) in which the frontal pose of the face of one horse reveals that the method of control was based upon the "Nasenbandzaum" tradition. We must keep in mind that the positioning of the horses' legs (charging position) and that of their heads is purely artistic. I suspect that the downwardly directed heads indicate that there is the burden of a heavy load. The other pose, however, is simpler to analyze: it reflects the quickly advancing chariot.

16 Herold, Streitwagentechnologie, XXV (glossary), 9-10, and 135-6.

17 They are regularly carved with regard to the advancing Hittites in Phase III (west wall, north side and north wall). I presume that this reflects the presence of different carvers.
Bersani and Dutoit argued that the apparent reduction of difference to sameness was all too often challenged by the Neo-Assyrian sculptors in such a way as to avoid in a purposeful fashion a continued series of exact duplicates. ${ }^{20}$ We can see this stylistic strategy even more by examining the third series of chariots. The left man once again is the charioteer. Yet at this point the artists have rendered him in a third pose, one in which his left hand duplicates that of the first chariot group but the right is raised. Combined with this new position, one that reveals the reins now once more held in the right hand, the heads of the horses face down. Evidently, the two equids are not subject to a pull as strong as is present in the second group. But we must keep in mind that the reins are virtually absent in this group. They were once more forgotten to be carved except for the beginning of those held by the right hand of the charioteer. Finally, the front portion of the horse does not curve as sharply as those horses whose heads are more sharply set at an angle. From this perceptible difference, we can reconstruct the position of the horses' heads when the scene is only partly extant.

Perhaps significant as well is the lack of a fourth walking man. Instead, we see the right leg of a footsoldier who marches immediately above. But preserving an A-B pattern is the presence of the front right leg in the air and the left on the ground; the rear legs coincide with the first set. Group three therefore parallels the first. But there are only three men next to the chariot. Was a fourth forgotten?

The next series of two chariots can be summarized in a similar fashion:

Fourth Chariot: The charioteer has his hands carved in a pose identical to the second group and

Some of the reins were not carved with the latter when they overlapped the shield: see pl. XIV (second chariot from the right) in NAVILLE's publication, for example. Others can be added. Here, questions of direction and attempts to present the pictures within an established framework may have affected the final outcome.

18 We must keep in mind that these details probably reflect the individual carver's interests. I find it hard to believe that such specific representations were presented to the man working on the wall. Rather, I hypothesize that some type of cartoon was employed as a standard for these repetitive cases.

19 L. Bersani-Ulysse Dutoit, The Forms of Violence. Narrative in Assyrian Art and Modern Culture, New York 1985, passim, especially pp. 8-23.

20 Ibid., 57-103. 
the horses' heads follow the same pattern. The front left leg is on the ground and the front right in the air; the rear legs operate in the expected pattern. Hence, there is an alteration of $\mathrm{A}-\mathrm{B}$, a system that is followed subsequently throughout this depiction. Five men walk to the right: two precede three. Is the missing one noted earlier here? The reins were not carved.

Fifth Chariot: The reins are held identical to the second chariots and the horses' heads are at the expected acute angle. But the reins are mainly missing. Only a loop held by the right hand of the charioteer is present. Three men walk at the right side of the chariot; two precede one. The legs continue with pattern A.

Sixth Chariot: The reins should have followed the previous arrangement but they are partly absent. The legs use pattern B. Owing to the break in the wall, it is impossible to analyze the position of the horses' heads. Two men, however, are carved behind the chariot, but they are not side-by-side.

Seventh Chariot: Except for the presence of pattern A, the rein situation appears to be identical to the preceding. Two men are behind the chariot and side-by-side.

Eighth Chariot: Pattern B is followed. Two men are to the right and the situation of the reins is unclear, but they probably were not carved.

Ninth Chariot: Pattern A holds. On the other hand the reins are held solely in the right hand while the left holds a baton. Two men march to the right but they now carry the large Egyptian shields. ${ }^{21}$ The heads of the horses remain at the expected angle, and the reins were partly carved.

Excluding the situation of the incompletely rendered reins, these first segments of the march of the $\mathrm{Na}^{\mathrm{c}}$ arn reveal minor but nonetheless important differences among the standard pattern. Individuality of chariotry control can be observed and there is an interesting variance with respect to the marching footsoldiers: 4-4-3-5-3-2 (one behind the other) -2-2-2. Once more some of Bersani and Dutoit's comments with regard to Assyrian narrative art are pertinent. ${ }^{22}$ Whether or not we want to view these intricate details as indicative of an artistic fetishism is not the issue. Rather, I prefer to interpret these differences as an attempt at diversity through regularity, a point that the two scholars also covered, but not in so much detail. We must grant, however, that this diversity is restricted in a formalized setting to minor issues. That is to say, the frieze of chariots was the issue for the artist and not such intricate details such as horses' heads. Yet it remains the case that these alterations provide to the viewer a degree of realism and relaxation. Indeed, a constant A-B-A-B etc. system is fatiguing on the eyes, although it was maintained with respect to the front legs of the horses. At this point the system alters somewhat owing to the approach to the battlefield:

Tenth Chariot: Pattern B is followed and the reins still continue with their "normal" arrangement, but are only partly carved. The men marching to the right have shields, and they are also depicted in a partly overlapping fashion, although it is again evident that one is located to the rear of the other. The heads of the horses retain the small acute angle. By an error, the bowcase at the side of the chariot is carved under the quiver. See our comments on this matter later on in the discussion.

Eleventh Chariot: Here, the left hand of the charioteer is lowered while the right one is raised to hold all of the reins. Hence, group eleven follows group three, and the reins were apparently meant to be held in one hand, the right. Pattern A is present and there are once more two footsoldiers who carry shields.

Twelfth Chariot: The reins appear to present the common pattern as, for example in group ten. Nonetheless, the horses' heads are facing downwards as in the third set. This may be of some significance because the following chariot reveals the quickened pace of this division of Egyptian troops. ${ }^{23}$ That is to say, the original arrangement of chariots has now decidedly altered and this group ends the first pattern. Two men with shields march to the right.

Such a partial standardization of representations seems reasonable, if only as these slight alterations lend a degree of verisimilitude to the entire border. Or to put it another way, the changes are minor even though they reflect to no small extent the reality of chariotry, drayage in particular. But except for the explicit patterning of the four legs of the two horses tethered to their chariot, no precise arrangement is extent. To take a case in point: the vertically directed horses' heads in groups three and twelve turn out not to form a unity. The third presents the

\footnotetext{
${ }^{21}$ This is clearly evident.

${ }^{22}$ The Forms of Violence, 66-72.
}
${ }^{23}$ This is best seen in NAviLLE's line drawing in Détails relevés, pl. VII.


reins held in the right hand whereas the tenth has them held in both hands, a posture that may very well indicate the speeded-up movement towards the fight although case eleven appears contradictory.

All in all, we witness a highly developed artistic means of pictorial representation in which slight alterations can occur without forming any regularity. For this reason I feel that we cannot fall into overinterpreting these groups. Errors could abound, and we have already observed the problem of the incomplete rendering of the reins. Still, the end result of the marching soldiers reveals the switch to a more protected group of two soldiers, a point that reflects the switch to a more warlike phase.

Only the horses' legs form a perfect symmetry of A-B. At this point we must correct an earlier remark of Heinrich Schäfer. ${ }^{24} \mathrm{He}$ maintained that problems of direction could arise when a single isolated figure is carved, independent of it being in profile whether at rest or in motion. According to him, the typical Egyptian striding figure represented in relief should always stand with the left leg advanced. The question of this deliberate choice has now been firmly analyzed by Gay Robins. ${ }^{25}$ In fact, the art historian Meyer Schapiro avoided any conclusion with regard to a "natural disposition" on the part of the artist or a possible superstition underlying the overt choice. ${ }^{26}$ But when transposed to the field of relief "the choice of leg to advance is determined by the direction of the profiled body". ${ }^{27}$ In other words, if the animal faces left, the right leg is advanced, and viceversa. Now all of our horses face left and yet both right and left leg are advanced. Perhaps this anomaly can be reduced in significance if we consider the rightmost equid (extreme south of the west wall) is considered to be the first to be read. Moreover, the last pair of horses in this first section, the twelfth, advances with the right leg forward. Here, as well, Schaefer's basic rule may be applied, so long as we

24 Heinrich Schäfer, Principles of Egyptian Art, John Baines, trs., Oxford 1974, 301-2.

Crucial for this and the following analysis is VON RECKLINGHAUSEN, ZÄS 63 (1928), 14-36; and H. FISCHER, L'écriture et l'art de l'égypte ancienne. Quatres leçons sur la paléographie et l'épigraphie pharaoniques, Presses universitaires de France, Paris 1986, 55 and 82-3. For Gay RobIns' analysis, which I follow, see the next note. SCHÄFER also discussed the situation of overlapping of figures with regard to the war camp of Ramesses II on pp. 186-9 of his work.

25 G. Robins, Proportion and Style in Egyptian Art, Austin keep in mind that the entire unit of chariots demanded the alteration of left-right (or reverse). Schapiro attempted a spatial interpretation for Schaefer's contention; namely, that in the round the horse was conceived to be moving to the right. ${ }^{28}$ The left leg is advanced because it is the farther one of the pair from the observer's viewpoint. I will leave these analyses for the moment but to anticipate, let me remark that the second section of horses that face to the right commences with two that advance the right leg. Thus, the end of either grouping of the chariots we meet four horses that show us the outermost leg: left when they face left and right when they face right. But the two animals constitute one group of the fast-moving four chariots. Behind them is the final or twelfth pair of horses. ${ }^{29}$ They show the right leg advancing. Here, the artists have moved from right leg (twelfth pair) to left (the four pairs of galloping horses).

Even the footsoldiers marching behind or to the right of the chariots are irregular in layout. Perhaps we can assume that the presence of three men instead of four was a slight error. Yet how do we interpret five? I cannot but conclude that, notwithstanding the accuracy of portrayal, the artists themselves were allowed a degree of freedom in choosing their presentation. This interpretation receives great support when we turn to the other Kadesh pictorial representations at the other temples. Abu Simbel, for example, does not parallel Abydos at this point; neither do the other scenes. It is hard to assume that the master designer or artist was so pernickety as to demand the faces of the equids to form such an irregular pattern as we have seen. Likewise, I suspect any interpretation that demanded a specific series of men to adhere to the pattern of 4-4-3-etc. Indeed, in some cases I feel that there have been irregularities, errors if you will. Whereas I do not believe that there was an intent to "subvert"
1994, 16-21. It goes without saying that I have bypassed the more general analyses of H. A. GROENEWEGENFrankFort, Arrest and Movement, London 1951, 121-41; and W. STEvenson Smith, Interconnections in the Ancient Near East, New Haven 1965, 168-79.

26 Meyer Schapiro, Semiotica 1 (1969), 223-42.

27 Ibid., 232.

28 Ibid.

29 The twelve chariots moving left versus the additional four charging versus the four moving right might be noted. See below. 
the narrative, as Bersani and Dutoit have observed with regard to their corpus of Neo-Assyrian war reliefs, I nevertheless feel that a degree of artistic play has entered at this point.

If we refer back to Johan Huisinga's concept of "homo ludens", then the idea of play as a quality of freedom marking "itself off from the course of the natural process" may be of some use. ${ }^{30}$ The Dutch historian placed emphasis upon the competitive nature of the plastic arts, but avoided any detailed study of specific cases of sculpture in the round or wall relief. The desire to break up repetitious portions of large depictions was also avoided by Huisinga in his significant volume. On the other hand, his general analysis holds with respect to our narrow case. Namely, that a freedom factor that effectively proves the individual nature of the creation was and is contained within any artistic performance whether frozen in relief or fluid in time (such as music).

But surely any appreciation or study of these battle reliefs implies time, that is, the movement from one portion of the scene to another. ${ }^{31}$ This is, in fact, what we have done above. By proceeding slowly from the extreme right hand side of the exterior west wall at Ramesses II's Abydos temple to the middle, we have traversed our own elapsed time. Similarly, the movement leftwards (from south to north) presents a different timeframe, one in which the $\mathrm{Na}^{\mathrm{C}}$ arn troops are proceeding to the battlefield. Hence, as with a melody whose notes recede back in time but are still maintained to some degree in our consciousness (via the linking of themes, motifs, movements), these Egyptian scenes are connected and so do not present a single event at a specific point in time. We should not read these groups of chariots as independent and single entities. These groups march all together. Their theme is self-evident; they are meant to be understood as a unit. Nonetheless, individual notes, to retain our musical metaphor, keep popping up. These separate and unique forms - chariot groups in our case - are not be meant to be akin to tones vanishing in the consciousness. Rather, "to each presentation is natural- ly joined a series of presentations", only in this case they all form a cohesive unity. ${ }^{32}$

The succession of chariots overtly leads to the speeded up movement in the middle of the western wall. Therefore, carved to the extreme right (south) are a series or groups of chariots that give us the sensation of time, or to be more precise a sensation of succession combined with a succession of sensations. The former is self-evident but the latter cannot be disregarded. Our minute analysis of merely a few pictorial elements has revealed that, if individually seen and analyzed, all of these groups present different sensations. Therefore, I maintain that these differences are more than mere ludic aspects that reveal the individuality of the artists and their schemas. Instead, they effect the visual whole through secondary differences that attempt to adhere to what would have actually been seen. In short, they reflect a desire to be realistic. At the same time, as I have stressed earlier, no exact pattern can be argued with the exception of the alternating legs of the horses.

A similar but not exact parallel can be observed in the next section of chariots. At this point, a quickened movement is depicted. The horses rear up in front and the reins are held by the charioteer in both of his hands. There are four such cases (Fig. 3). ${ }^{33}$

First Chariot: No left-right or A-B pattern is followed because the quick arrival of the troops into the camp has now occurred. Equally, there are no supporting footsoldiers to the rear (right) of the chariot. The heads are at the same acute angle as we have seen previously and the reins are in both hands. In this case the distance between the right and left hand is small. In similar fashion, the space between this first group and the second is greater than with the preceding groups. That came about owing to the desire to reflect the fast movement into the camp. Finally, the bowcase is carved under the quiver.

Second Chariot: The hands of the charioteer are raised upwards but he holds the reins as previously. It is noteworthy that the front legs of the two horses overlap the tails of the horses that precede.
${ }^{30}$ J. Huisinga, Homo Ludens. A Study of the Play Element in Culture, R.F.C. Hull, trs., Boston (1955) 7. But war is deadly, even though it may involve "play". See my brief remarks in the review of HEINZ, JAOS 102 (2002) 127 note 8 .

31 GABALLA adumbrates this situation in his study cited in note 1. It is part and parcel of the later works of Müller and HeInz.

${ }^{32}$ E. Husserl, The Phenomenology of Internal Time Consciousness, James S. Churchill, trs., Bloomington 1964, 30.

33 We should once more keep in mind the antithesis of four versus twelve. 
Indeed, they cover the front (right side) of the chariot platform.

Third Chariot: Once more the charioteer's hands are different. The right one appears to hold the reins and the left not. However, the left hand is in an arched position, as if it originally was meant to be in action. But it is higher than the right, the first time that this pose has occurred. It is significant that the third group presents the heads of the horses facing down, exactly as was carved in a few of the first series of chariots. In addition, this group overlaps even more with the chariot to the left as the horses' legs now reach the middle of the next two horses. The bowcase is under the quiver, resulting in an A-B-A pattern.

Fourth Chariot: The heads return to the expected angular pattern. The reins are not held in the same fashion as in the preceding figure. Instead, the hands are low, exactly as may be found in the first group in the preceding section. The shield cannot be seen because the horses in the previous chariot have blocked the view. The bowcase is above the quiver resulting in an A-B-A-B pattern.

Although we have reached the base line of the camp - the protective shields surrounding it commence with the second fast-moving chariot - no more Egyptian chariots are seen. In addition, it is reasonably clear that the final group might show the charioteer slowing down his rapid motion by pulling back his two horses. On the other hand, it is more likely that he is simply preparing to support the beleaguered troops of his king at the camp.

Split neatly by the relatively thick groove in the wall that was used to support a flagstaff is the following contrapuntal scene. Here, the direction is reversed. ${ }^{34}$ Although a break of around three meters breaks up the plan, enough remains to establish a different pattern. Three footsoldiers are carved behind an empty chariot that facers right (south). Naville remarks that "the drivers get down from their chariots". ${ }^{35}$ But this is not accurate, a situation which Wreszinski explained better. ${ }^{36}$ These troops may have belonged to the advance guard of the king's first division that were resting next to the
Orontes when the Hittite spies were interrogated. Most certainly, we are witnessing a quieter scene. The charioteer holds the reins of his horses but he stands to the read of the platform waiting for instructions. The three footsoldiers carry shields as the $\mathrm{Na}^{\mathrm{c}}$ arn troops do, and they likewise face to the left, but the chariots are ready for action (or departure) to the right. In other words, the direction of sight continues from the right (south) but the temporal setting is different.

The placement can be specified. These soldiers do not interact with the preceding $\mathrm{Na}^{\mathrm{C}}$ arn troops. Hence, all of them must be considered to belong to a separate scene, a conclusion that is inherent in Kitchen's outline of the wall. ${ }^{37}$ Müller, as well, felt that the first division (Amun) is depicted, and that they appear as if the Hittite attack is occurring. ${ }^{38}$ Wreszinski pointed out that the chariots were somewhat more graceful in comparison to those of the $\mathrm{Na}^{\mathrm{C}}$ arn. ${ }^{39} \mathrm{He}$ further reflected on the equipment of these chariots in combination with the careful restraint held upon the horses. The parasol and perhaps the large disk indicate the royal chariot. ${ }^{40} \mathrm{We}$ shall refine this analysis later, but for the moment a detailed survey is needed.

First Chariot: The heads are at the assumed acute angle. The positioning of the horses' body is a mirror image of those discussed: the right front leg is raised and the rear is forward. This will be reversed for the second group of horses and so forth. I.e., the legs that we see in both the first section and this one are raised and in front. Pattern A-B emerges but this time read from the front of the scene instead of the rear. The man waiting and holding the reins uses his left hand to prevent the horses from moving.

Second Chariot: The horses' heads face down and the left legs are forward.

Third Chariot: The heads return to the acute angle and the right leg moves ahead.

At this point the relief is broken and there is around three meters missing to the left. Subsequent to this regularity is the last and most important chariot. It carries a fan and has the disk on the head pole that I have noted earlier. The scene is easy to place

\footnotetext{
34 This must have been planned. Therefore, the neat juxtaposition of four chariots moving left - the charging ones - and the four that face right reflects the exactitude of the designer.

35 Détails relevés, 17.

36 Atlas II, pl. 18.

37 KRI II 128.
}

38 Die Thematik der Schlachtenreliefs, 79.

39 Atlas II, pl. 18; see LitTauer-Crouwel, Wheeled Vehicles, 76-7.

40 The scene is best rendered in the photograph of Wreszinski, Atlas II, pl. 18. LitTAUer, Antiquity 48 (1974), 293-5. This is the disk on the head pole. 
in time. We are shown the troops prepared to attack. This must have occurred after the camp had been attacked by the Hittite chariots. Therefore, the second Egyptian division (Pre) was already scattered by the surprised Hittite attack across the Orontes. The final right legs of the chariot horses move forward, and owing to this there must have been an even number of chariots preceding. Last but not least, although the heads of the horses are missing owing to a break, we can reconstruct their position to parallel the second group: they must have faced downwards as can be ascertained by the angle of the front of the horse. If this reconstruction is accepted, then a system of A-B works within the limited nature of these four immobile chariots.

A third grouping now takes over: guardsmen holding, in an alternate fashion, either a sickle or an axe (Figs. 4, 5). They form the base of the scene of the spy episode. Only text R 8 is present, the one that described the capture of the Hittite spies and their interrogation. Kitchen correctly places the Bulletin (part of which is preserved) and the seated king dealing with these recalcitrant scouts, who are subjected to a sever bastinado in order for the king to elicit the actual situation in the field. ${ }^{41}$ (Parts of B 25, 27, 29, 30,31 , and 33 are preserved). The system works as follows. There are sixteen men. Each holds a war implement - axe or sickle - but at different angles. The last five hold them more upwards whereas the remainder carry them in a less relaxed fashion. Man number six from the left has his axe held in an intermediate fashion, betwixt and between the two standard positions, perhaps forming a transition. This, however, can be seen to be a minor individual quirk by the carver. The location of the hands grasping the axes varies somewhat and there is no rule. But the hands clutching the axes are carved in two differing positions, both of which coincide with the major split of pose. In the group of five to the left the men's hands are placed near the end of the shaft; the ones to the right are located closer to the blade, in the middle of the shaft to be exact. The arrangement of the weapons is presented from right to left (south to north) in this fashion ( $\mathrm{S}=$ sickle; $\mathrm{A}=\mathrm{axe})$ :

${ }^{41}$ KRI II 128; MüLLER, Die Thematik der Schlachtenreliefs, 79 follows him.

42 The best study of foreign helmets in Western Asia at this time (Late bronze Age) is that of Tімотну Kendall, gurpisu ša awēli: The Helmets of the Warriors at Nuzi, in: M.A. Morrison, D.I. Owen (eds.), Studies

\section{S-X-X-X-A-S-A-S-A-S-A-S-A-S-A-S}

Note the slight change in the pattern with regard to the first five men to the right (south). This pattern can be augmented by our previous remarks concerning the position of the weapons $(\mathrm{D}=$ down; $\mathrm{U}=\mathrm{up})$ :

$\begin{array}{llllllllll}\text { S } & \text { X } & \text { X } & \text { X } & \text { A } & \text { S } & \text { A } & \text { S } & \text { A } & \text { S } \\ \text { D } & \text { D } & \text { D } & \text { D } & \text { D } & \text { D } & \text { D } & \text { D } & \text { D } & \text { D } \\ \text { A } & \text { S } & \text { A } & \text { S } & \text { A } & \text { S } & & & & \\ \text { D } & \text { U } & \text { U } & \text { U } & \text { U } & \text { U } & & & & \end{array}$

It is by no means insignificant that the separate group of soldiers are placed under the three columns that remain of the hieroglyphic version of the Bulletin. Again I cannot but conclude that a highly intricate layout of the Abydos version of the Kadesh Battle was planned and executed. Let us also remark that the number of these guardsmen are sixteen. The number of chariots that face forward from the extreme south of the west wall is divided into twelve and four. I.e., they also amount to sixteen. I doubt that this results from mere coincidence. Finally, there are the shields. All of these sixteen men carry them on their left side; their right hands logically are equipped with either of the two weapons.

A slight space separates the forward or left facing guardsman from the row of Sherden who are located in front of them (Figs. 5, 6). Carrying their round shields in the left hand and their long spears that hang on their backs, these men grasp their short daggers in the right hand; even their helmets differentiate them from the Egyptian troops. ${ }^{42}$ Once more a depression in the wall meant to hold yet another flagstaff can be seen, and here as well the carvers worked within the cavity. These men, as the preceding, march with their right leg forward. Hence, it is simple to conclude that the positioning of human legs still follows the accepted paradigm and unlike the equids, no alteration is shown.

Because the Sherden are the elite guard who protect the Pharaoh, and because the king is located above on this thrown dealing with the two spies, we can assume that these men are meant to be facing us. That is to say, they face outward to the viewer. Eight of them are directed to the left and another eight, on the Civilization and Culture of Nuzi and the Hurrians, Winnowa Lake 1981, 201-31. His data cover Dynasty XVIII. For Egyptian evidence of Mycenean warriors and their helmets: L. Schofield, R.B. PARKInson, ABSA 89 (1994), 157-70. 
sixteen in all, face right. The second group, of course, place their left leg forward. The two Sherden who face each other are conveniently if not aesthetically drawn with their daggers overlapping. All of the angles of these weapons are the same, but the acuteness of the angle is less pronounced than with the five Egyptian soldiers to the immediate right. Wreszinski speculates that perhaps more standing files of these Sherden served to protect Pharaoh on his two sides or before the throne. ${ }^{43}$ Whether this is correct or not we cannot say. Nonetheless, these soldiers as well as the facing Egyptian troops have yet to see battle. But, and this is an aspect not overlooked by Wreszinski, the Sherden wear the same kilts as their Egyptian companions in arms.

The angle at which the Sherden hold their short swords bears analysis. Here, we can immediately notice that a rough forty-five degree line can be drawn down from the underside of the weapon to the angle of the soldier's kilt. In other words, they align the eyes of the viewer upwards to where the king is sitting (now lost), but more importantly where the spies are being punished. ${ }^{44}$ In that bastinado scene the long stick held by an Egyptian punisher cuts a further forty-five degree, this time to the left. In addition, the entire group of right facing and left facing mercenaries focuses the attention upwards, for the angles center upon the two key Sherden facing each other. If we raise our heads above this point, then it is to the corner of the camp that our heads will be drawn. Such a planned scene is further emphasized by the location of the Bulletin. As Kitchen drew in his plan of the west wall at Abydos, that somewhat lengthy inscription is to be read, in a vertical fashion, from the extreme left (north) to the right, and there the columns range further down. ${ }^{45}$ Or to put it another way, the Bulletin surrounds the scene of the seated king plus the bastinado of the spies with the Bulletin moving downwards at the exact point where the first left facing Egyptian soldier is carved. All was carefully planned.

Behind the Sherden and to the left are more Egyptian footsoldiers (Figs. 6, 7). They, as well, are not prepared to fight. Instead, they face due right and form a useful balance to the Egyptian troops who face left and are located immediately behind the Sherden. The angular motion upward is no longer directed through spears but by means of a slight bend in the backs. In order to clarify this point, the posture of all of these footsoldiers needs to be detailed. Moving from the center to the right we have Sherden and Egyptian troops and to the left Sherden and a different assemblage of native soldiers. The angles of the spears and swords that the Sherden carry operate to direct the eyes upwards. The spears are long and form an approximate angle of seventy-five degrees whereas the short swords are held about forty-five degrees to the horizontal. The Egyptian footsoldiers on the right carry their spears at the same angle as the Sherden but their weapons (sickles and axes) are positioned differently as we have seen above. Nevertheless, the direction of eye movement is still forced upwards to a center. On the left and behind the Sherden march a second group of Egyptians. They are bent forward as the previous native contingents. The heads of the Egyptians follow the posture of the slight angle. That is to say, they face somewhat downwards. Because the helmets of the Sherden are small, their faces are more exposed. As a result, their heads more clearly coincide in direction to the spears that they carry. Direction, therefore, is more strongly indicated through the Sherden than the Egyptians.

But the scene remains unified. Here we have the events in the king's camp depicted above; the preparations for the counterattack have yet to take place. In other words, the motion in time is backward to the direction that I have been reading. This I have purposely done in order to emphasize the careful artistic placement of chariots, horses, and soldiers, while ignoring for the moment the correct historical sequence of battle.

These additional Egyptians are protective troops. The first man holds a bow and he is devoid of shield although he carries a quiver. ${ }^{46}$ His bow overlaps in the front of the shield of the final Sherden mercenary. More importantly, it is held higher than that of the following man and diverts our attention to the

43 Atlas II, pl. 19.

${ }^{44}$ At this point we can return to the analysis of BERSANIDutoIT, The Forms of Violence, 66-103.

45 KRI II 128; this resolves the tentative remarks of GARDINER, The Kadesh Inscriptions, 3; see MüLler, Die Thematik der Schlachtenreliefs, 79-80.

46 Only the first two men have quivers held on their backs. The following Egyptian troops are shieldbearers and carry their small weapons. 
scene of the spies immediately above. I assume that this "hidden" characteristic was employed to focus attention to the main scene of the bastinadoing. The second man is also an archer. Both he and the first man have nothing in the right hand. No arrows can be seen in either quiver. The two individuals bend forward in a pose identical to the Egyptian troops to the right. This second man carries his bow at a less acute angle than the first. From the third man leftwards a more regular pattern can be discerned:

Third Man: He carries a shield on the right hand and a stick in the left. This could be an error on part of the sculptors, a situation that will be discussed below. For the moment let me stress the fact that the following two men also carry sticks. The latter are angled somewhat differently; however, the difference is insignificant. The poses are: near horizontal; a larger acute angle; and a slightly shallower angle. The sticks are naturally not mere pieces of wood useful for beating. First, the one held by the fifth man has a point. Perhaps this weapon is equivalent to the javelin. On the other hand, it is short and not notched at the end except for the one held by the seventh man (see below). Owing to this I prefer to view the sticks as a separate implement assigned to the king's guards. Yet one is also notched at the end, a point that we cannot overlook owing to some key presentations at Abu Simbel. (See Part II below for a more detailed study.)

Fourth Man: He is drawn in the same pose and manner as the previous soldier. The arrow, however, is held lower so that it only reaches the top of the first soldier's waist girdle. The other tip of the bow just hits the right leg above the knee. (Incidently, this gives added proof, if it was needed, to the supposition that when the men face right it is the left leg that is located in the forward position.) He and the following soldiers carry a shield on the right arm, but here the man's stick is carved at the highest acute angle.

Fifth Man: The stick has a pointed end and is held at a moderate angle.

Sixth Man: We reach the first soldier who grasps an axe. It is held virtually horizontal and so does not parallel those grasped by the Egyptian soldiers on the right.

Seventh Man: He grasps a short dagger in the right hand.

Eighth Man: He has a stick and it is double pronged at the rear.

Ninth Man: He has a dagger.

Tenth Man: He has a sickle sword but one that is shorter than those held by the Egyptians to the right.
Eleventh Man: He has a stick; it is impossible to determine if it is double pronged.

Twelfth Man: He has an axe.

Thirteenth Man: He also has an axe.

Fourteenth Man: He carries a double-pronged stick.

Fifteenth Man: He carries an axe.

Sixteenth Man: He has a double-pronged stick held more acute than the preceding or the following man.

Seventeenth Man: He has an axe.

Eighteenth Man: He has a double-pronged stick.

Nineteenth Man: He has an axe.

The arrangement of the implements held by the men following the first two archers is somewhat vicarious $(\mathrm{S}=$ stick; $\mathrm{A}=$ axe; $\mathrm{SI}=$ small sickle; $\mathrm{D}=$ dagger; $d$ = double pronged):

S-S-S-A-D-Sd-D-SI-S?-A-A-Sd-A-Sd-A-Sd-A

I doubt if we can argue for any regularity here except for the final three pairs. Once more I feel that individual traits are shown by the artist carver without a requirement that a certain set pattern be followed. But it is remotely possible that some of the sticks were not completely carved, and that the original design was to be a hand axe.

This scene is now complete. The following one, still located on the west wall reveals an entirely new situation (Fig. 7). We are now set within a new event, but one that does not correspond with the scene of the spies (nor the Bulletin account) located above. Here, the Hittites have attacked. The movement is first to the left and thus we are forced, without any vertical line of demarcation or even the corner of the wall to treat this depiction separately. Merely by the turn of direction the focus is altered.

One Hittite has been caught on the ground and he is quickly being done away with. An Egyptian archer has grasped him by his top hairs and is ready to give the enemy the coup de grace. Following him to the left is a Sherden who proves to be as doughty as his Egyptian counterpart. The mercenary is prepared to slice the throat of a Hittite. Then comes an Egyptian about to stab a Hittite in the chest with his spear. Finally a second Sherden is depicted, this time at the moment of cutting off the left hand of the enemy. Ultimately, the hand will be dropped in a pile for counting at the end of the slaughter. In this case the enemy is prostrate and I feel it reasonable to assume that he is already dead. Then comes the water of the river Orontes and a different portion of the action.

It is readily ascertainable that we have passed to the second portion of the battle reliefs. The conflict has broken out; the only question is where? Naville 
was the first to indicate the problems surrounding this scene. ${ }^{47}$ It continues around the corner of the wall and runs further back on the north wall. There, various Hittite chariots are advancing to the Egyptians. By the time we move back to the west wall we immediately perceive that the scene continues. In other words, the movement from north to west wall does not interrupt the flow of activity or, in fact, the unity of the action. There can be little doubt, then, that this portion of the reliefs is devoted to the onslaught at the Egyptian camp at the time that the Hittites had reached Ramesses' fortified position but before the $\mathrm{Na}^{\mathrm{c}}$ arn had arrived. Noteworthy is the location of the latter: they are diametrically opposed in location and in time to the Hittite attack. Since we are still below the camp, it is clear that this scene must reflect the immediate onslaught of the Hittites at Ramesses' camp. These depictions therefore do not reflect the earlier attack against the king's second division. ${ }^{48}$

There is a boundary line of water running into the lower water frieze, the latter of which serves as the bottom of the pictures. Naville stated that this descending stream must be at one of the fords, clearly of the Orontes. ${ }^{49}$ From the detailed portions on the north wall the actual topography has been reversed. Ramesses stood to the west (or left) of the city of Kadesh. Muwatallis, his opponent remained on the right side of the river where Kadesh also was situated. Yet at Abydos the north wall reveals that the king had to have been carved attacking his enemy above the city and to its left (west). Here, the artist has placed the king correctly but separate from those chariots moving close to the base of the depiction. For this reason we have to separate the lowermost scenes of battle from those above, just as we have regarded the other depictions in this study. We certainly cannot regard this portion of the battle as reflecting the final push of the Egyptian over to the Orontes. That segment of the action is recounted in Phase II of the reliefs and is placed, as I have stressed, in the upper half of the northern wall.
With this in mind, let us first return to the four defeated Hittites. The order is pleasantly arranged: Egyptian-Sherden-Egyptian-Sherden.$^{50}$ Then too, four separate means of victory are indicated: scalp (? Naville's possible interpretation $)^{51}$ or decapitation; neck slice; spearing; and hand cutting of a dead man. In other words, the artists have rendered schematically though effectively four possible outcomes of the enemy's loss. No chariots may be seen in this grouping of enemies. I think, however, that we have to assume that they arrived by those means. Hence, the small scene is even more schematic, being a simply pictorial carving in which a summary of the attack on the camp and its results are indicated. This interpretation is further supported by the lack of military armament held by the enemies. There are no weapons next to the four enemies, and not even their shields are present. Perhaps we can assume that the horses had run away with their chariots.

The angle of the four Egyptians and Sherden runs acutely to the left at an angle of about sixty degrees. Conveniently, it matches the angles of the river. Added to this purposeful motion are the angles of the advancing Hittite chariots. They are placed in a position of about sixty degrees as well, but this time because they move rightward the two angles form a nice equilateral triangle with the river set in the middle. The first horse rears up frontward at the greatest angle, thereby indicating the direct onslaught. The animals in fact cross over the river or ford with the four front legs on the right side and the four rear legs on the left. The prostrate body of the enemy covers the entire body of water but here, as well, we must regard any topographic representation as unreal.

The chariot attack of the Hittites is virtually connected to the schematic slaughter of their four compatriots. Only the dividing water and its line of direction, paralleled by the four back lines of the successful Egyptian/Sherden opponents, provides a break. Yet this split in scene is only partial. We are meant to view the Hittite onslaught up to and over

47 Détails relevés, 17 . The interpretation ventured here does not correspond with MüLLER's analysis in Die Thematik der Schlachtenreliefs, 79-80.

48 And if only for this reason we ought to separate the frieze, mainly devoted to advancing Egyptian and Hittite chariots, from the main actions above.

49 Ibid., 17: he specifies the location as "the river". This is

obvious: see, for example, the brief comments of WresZINSKI, Atlas II, pl. 21.

50 The men are: archer (see the quiver); Sherden; spearman (no quiver); and Sherden. They must have belonged to the personal guard of Ramesses. The two Sherden employ their short daggers.

51 Détails relevés, 17, 19. 
the water. The prostrate and undoubtedly dead Hittite who crosses over the river effectively indicates that the two phases of battle are interconnected.

We can stop our horizontal trajectory at the point of this encounter at the point where the horses of the first attacking chariot rear up. Once more two intersecting lines of direction halt our eye movement, that of the underneath belly of the chariot horses and the angle of the Sherden's back, the man who is about to cut off the hand of enemy. More visually important, nonetheless, is the equivalent angle formed by the water, but in this case it runs down behind the rearing horses and behind the head and shoulders of the dead prostrate Hittite. To put it succinctly, angle movement plus opposing line of direction (Hittite charge from the left, Egyptian move to the left) form the node of encounter.

Hitherto, changes of personnel and direction were not so explicitly denoted. We have seen that the extreme right of the west wall commences with the march of the $\mathrm{Na}^{\mathrm{c}}$ arn chariots. At one specific point - a flagstaff depression - a change takes place. Here and to the left of the indentation a second scene is carved. The latter presents the chariots ready to move in a rightwards direction. But the men face still left, thereby partially linking the activity to the $\mathrm{Na}^{\mathrm{c}}$ arn. Further on and to the left the soldiers who protect the camp of the king move leftwards until the reverse is indicated at the precise point of the intersection of the two facing Sherden whose short swords or daggers overlap. At that point the direction is totally reversed as we now move to the right. Finally, continuing to the north (or left) we have seen the marching Egyptian footsoldiers, and it is only when we encounter the four acts of

52 The differences with regard to the Egyptian chariots will be described below. For the moment, see BEAL, The Organisation of the Hittite Military, 148-51. Note, however, the lack of bowcases, quivers, and spear holders on the outside of the chariots. (One exception in the Kadesh reliefs was cited by him: at Abydos the Hittite king's chariot has a bowcase although it lacks a quiver: NaVILle, Détails relevés, pl. XVI and Wreszinski, Atlas II, pl. 21a.) BEAL also stressed the fact that the archer wore his quiver on his back, but that a bowcase was probably attached to the cab. There is no indication here.

BEAL (p. 148) made the further point that in a crucial and well-known relief of Seti I at Karnak (scene on the exterior north wall, west side, of the hypostyle court: Epigraphic Survey, The Battle Reliefs of King Sety I, Chicago 1986, pl. 34) the enemy chariots contain only two men, one carrying a bow and the other a shield. He then argues that a technological switch had occurred between slaughter that our eyes direct themselves to the left. But here as well the activity does not remain leftward directed for long because the advancing Hittite chariots move right (Figs. 7, 8).

These chariots appear on first viewing to be schematically rendered.$^{52}$ Only the first shows the high gallop and rearing of the two horses. The second team of horses, for example, is racing to do battle; however, it is not so ferociously positioned as the leader. Six chariots can be seen on this portion of the extreme north side of the west wall; then comes the corner. Suddenly, we are faced with anomaly. The lowermost scene runs around the edge of the two walls, west and north. Even though the scenes immediately above are different, those below are unified. To be specific: at the immediate left of the corner Phase II is carved. In other words, the corner separates the major depiction that is located above this lengthy frieze-like band of troops. Yet the latter continues around the dividing line. It is therefore incorrect to connect the lowermost band automatically with the scenes above. This is easily recognized by the dividing line of the river Orontes. We have previously recognized it as forming the key division of the onslaught upon Ramesses' camp. Further back, so to speak, it runs horizontal with the base line, forming an effective break that divides the detailed and large upper depictions from the smaller ones that lie just above the base line (or water in this case). Captions R 23 and R 24 further prove this contention. They are placed above the lowermost frieze scene and thus even above the horizontal band of the river Orontes. Owing to this, they clearly belong to the scenes carved above and not to those at the extreme bottom.

this time and the date of the Kadesh battle. But one can argue that the third man had fallen off the chariot. In addition, there remains the possibility of artistic convention influencing the design. Mistakes, as we have seen, could also occur, and the editors of the publication The Battle Scenes of King Sety I, 108-09 have noted the problem with the Pharaoh's chariot. I could add one odd-looking Hittite on pl. 34. In the lower right portion of the relief the second man from the right who has been struck by a spear looks remarkably Egyptian. The helmet is the main indication of his ethnicity, but the lack of a ribbon-like plume can be brought into consideration. The latter point is not that significant; see, for example, the topmost enemy (the man who holds a bow) to the extreme right.

T. KeNDALL, The helmets of the Warriors at Nuzi, 215-19 supplies excellent detailed information regarding the helmets in Syria. 
The Hittite chariots can now be examined.$^{53}$ First let us cover the six that are located on the west wall. Unfortunately, the upper portions of the blocks are partly damaged and only a partial reconstruction can be attempted.

First Chariot: As previously stressed, the horses rear up at an extreme angle. The shield, a typical Hittite one, ${ }^{54}$ is held by the third man, the soldier furthest away from the viewer. The charioteer is located closest to the beholder and the remaining man is carved behind these two more active participants in the melee. The reins are held in both hands and a neat loop in them is expertly depicted. A spear or javelin is held in the right hand by the man in the rear and it aids in the upward motion of the scene. Note that the weapon is directed to the extreme right front so that we can see it overlap the charioteer and, of course, the shield, which is definitely held in the left hand. There are eight spokes to the wheel, a point that I have briefly noted above and will discuss later. ${ }^{55}$ They are drawn at hours one and one half, three, four and one half, six, seven and one half, nine, ten and one half, twelve.

Second Chariot: The horses rear up ready for battle, but not to the extreme degree as the preceding ones. The spear is not completely drawn and juts forward, this time behind the shield, which is quadrilateral in form. If this was meant to be an accurate representation then we have to assume that the spear is probably held by the shieldbearer in his left hand. I find this highly dubious, if only because the angle of the spear runs downward too sharply. The shield is held by the left hand. Finally, the chariot form is different from the Egyptian one: it lacks the fine curve at the side that gracefully moves downwards. ${ }^{56}$ This factor is

53 For the garments of the Hittite warriors, see BEAL, The Organization of the Hittite Military, 150-2 and Epigraphic Survey, The Battle Reliefs of King Sety I, 105 note 2.

54 This the famous figure eight shield. One must keep in mind that there are many slips of execution in the scenes of the battle of Kadesh. In particular, some of their chariots show one man (e.g., at the Ramesseum and Karnak). However, the frieze scene described here is regular in appearance. This was undoubtedly due to its formal aspect of presentation.

55 In particular, see note 58 below. But it is significant that the first chariot is the only one among this Hittite contingent that has eight spokes. One might prefer to view this representation as an artistic indicating of importance rather than reflecting historical accuracy. Indeed, could an Egyptian have remembered this fact?

56 The Hittite chariots also diffe somewhat from the Egyptian king's splendid one. In Seti I's battle scene important as it is only present when non-Hittites are in their chariots. ${ }^{57}$ See our comments below.

Third Chariot: Here, we return to the typical Hittite shield. An alternation of A-B is apparent. No spear is evident and the upward motion of the horses parallels the second chariot.

Fourth Chariot: The quadrilateral shield is present and the motion of the horses is standard. Unlike the preceding two groups this depiction renders the reins somewhat differently. Here, the right hand lacks the loop. It holds the reins but no loop is present. In its place the reins move over from right to left and then back again to the horses. I assume that the carving was incomplete at this point. No spear can be seen. The chariot is square at the rear.

Fifth Chariot: The shield is the expected Hittite one. A spear is evident, clearly held by the man somewhat to the back; its angle is moderate. The reins are held in common with the previous group.

Sixth Chariot: This group is too damaged to analyze.

Some additional points can be mentioned. In the first advancing chariot Hittites appear to be present. Moreover, the preparations for actual hand-to-hand fighting are reflected by the presence of the spear and its angle. The second chariot is, as we have seen, less prepared for the actual encounter, and the spear is thus carved in a more relaxed manner. The wheels are also presented in different pattern. The first and the fourth have one of the spokes at a perpendicular angle to the horizontal whereas the remaining four set the spokes in such a position as to form two fortyfive degree angles. ${ }^{58}$ This is useful to note if only as the other chariots to the right on the west wall totally avoid any ninety-degree angle. ${ }^{59}$ Even though minor variants may be noted among these chariots, it can be

the differences also not that remarkable: Epigraphic Survey, The Battle Scenes of King Sety I, pl. 34. One useful point, however, is the presence of a hole on the upper rear side of the Hittite chariots; this is never indicated on the Egyptian ones.

57 BEAL, 195-6, briefly notes the non-Hittites among the enemy in Egyptian reliefs.

58 The spokes are the normal ones for this time: six. See LitTauer-Crouwel, Wheeled Vehicles, 52 (four spokes), 69, 72 (earlier ones with four spokes), 78-80, and 90-3. $\mathrm{J}$. K. HOFFMEIER's study on eight spokes is useful: JARCE 13 (1976), 43-5, to which see his later study: The Chariot Scene", in: D.B. REDFORD (ed.), The Akhenaton Temple Project Vol. 2: Rwd-Mnw and Inscriptions, Toronto 1988, 35-45. In the later study HoffmeIER revised his opinion somewhat, ibid., 39. But the chariot wheel that Hoffmeier refers to has definitely eight spokes if the reconstruction is correct. See REDFORD, The Akhenaton 
stated that the rule was to avoid a vertical orientation. But noteworthy is the presence of the first Hittite chariot that crosses the river. It has eight spokes. Is this a mistake, or possibly a result of simple artistic preference? Insofar as there are other cases with eight spokes, there remains the faint possibility that some of the enemy's vehicles were heavier and so needed eight spokes. ${ }^{60}$
Temple Project I. Initial Discoveries, Warminster 1986, pl. 12 but note the stringent remarks of R. VERGNIEUX with respect to these restorations: Recherches sur les monuments thébains d'Amenhotep IV à l'aide d'outils informatiques, Geneva 1999. The earlier four-spoke chariot wheel is most noticeable in the war reliefs of Amunhotep II: ABDEL HAMID ZAYED, Une représentation inédite des campagnes d'Aménophis II, in: Mélanges Gamal Eddin Mokhtar I, Cairo (1985) 5-17 and pls. I-II. The spokes are vertical; i.e., they are at hours three, six, nine, and twelve.

This new evidence refutes HoffmeIER's earlier study in JARCE 13 (1976). In particular, the change in Egyptian chariotry must now be dated to ca. late Dynasty XVIII but pre Amarna. Note that in VeRGNIEUX's publication the spokes of the Egyptian chariots generally follow the hours of one, three, five, seven, nine, and eleven, exactly as HOFFMEIER wishes: VerGNIEUx, Recherches sur les monuments II, pls. LXXIII-IV. One example, however, does not: pl. LXXIII top (A0016). There, the spokes are placed at hours three, four and a half, six, nine, ten and a half, and twelve. In this case one must examine the artistic design. The chariot is at rest, and apparently the basic hours of three, six, nine, and twelve were employed to carve the spokes. Then the remaining two were placed, but owing to this they are incorrectly drawn. This last example is an excellent one as it reveals the necessity of checking very closely the artistic arrangements of each item.

S. HARVEY presents a very useful discussion of the Dynasty XVIII material in his The Cults of Ahmose at Abydos, University of Pennsylvania Dissertation, Philadelphia 1998, 302-72 and figs. 76, 78 (both crucial), 82, 91-2, 93-4 (the Thutmose IV example from his chariot), and 95-7 (suggested restorations).

The following remarks can be made with respect to Harvey's new data. First, the Thutmose IV example clearly reveals the king's chariot with eight spokes and the Asiatics with four. Owing to this, Harvey hypothesized that the same was reflected in the very broken scenes of Thutmose II. Unfortunately, there are no extant fragments from Thutmose II's mortuary temple that allow us to prove this contention. Nonetheless, while admitting the possibility, I wonder if the scene reflects the royal chariot. I.e., the artistic design does not reflect actuality. A second point worth considering is the number of the spokes of the chariot wheels that we can see. Two of them have four, set at hours three, six, nine, and twelve (fig. 78A). With Harvey, I assume that they belonged to the Asiatic enemy. A further fragmentary scene (fig. 78B and 91) reveals a more complex situation. Here, four wheels can be seen. The first on the left has at least four spokes set at hours two, four, six, and eight. But upon closer inspection I feel that there were originally six. The second wheel from the left is hard to interpret. I see a wheel spoke at hour seven and a half, possibly one at hour nine. The third from the left is the clearest. There are eight spokes set at hours one and one half, three, four and one half, six, seven and one half, nine, ten and one half, twelve. This is clear because the last chariot wheel (right side) only preserves part of one spoke (hour nine). See the following two notes.

${ }^{59}$ Hoffmeier discusses the angle of the spokes on the Karnak talatat (and elsewhere) in: The Chariot Scenes, 43-44. In the advance of the $\mathrm{Na}^{\mathrm{c}}$ arn the spokes are essentially at hours one, three, five, seven, nine, and eleven. The final four charging chariots show the spokes tilted slightly more, but the system is essentially the same. The four immobile Egyptian chariots follow the same pattern. The Hittites chariots, however, are somewhat different. See our comments in the next note.

${ }^{60}$ These can be most easy seen in NAville, Détails relevés, pls. XI (B, second from the left); XIII (top, fourth chariot from right, with the expected hour associations; a clear error), pls. XV (broken section, second chariot from the right; error?), XIX (top right; probably confused with the bottom of the chariot cab), XIX (right, third register from bottom; a clear error owing to the base line of the cab; seven spokes can be seen!); and XX (second register from the bottom). But confusion appears to have taken place owing to the flat bottom of the chariot cab: the two lines forming that border are often identical to the two lines forming the spokes. An excellent case can be noted on pl. XX (top register) where it first seems that seven spokes are drawn. Actually, there are six, which are set at hours two, four, six, eight, ten, and twelve. The "seventh spoke" is the base line of the chariot cab. But the chariot in the second register from the bottom reveals the problem in a nutshell: the base line of the cab is drawn running over to the other side of the wheel. Therefore, eight spokes appear although actually only six were intended, and set at hours two, four, six, eight, ten, and twelve. N.B.: all of these cases in which eight spokes are indicated place them at those hours whereas the regular ones of six spokes are set at hours one, three, five, seven, nine, and eleven. This is a further reason to question the existence of such heavier chariots within Egypt.

I feel that the following rule is possible even though many errors crept in. For chariots at rest, one set the spokes at hours two, four, six, eight, ten, and twelve. For chariots in motion the spokes were set at hours one, three, five, seven, nine, and eleven. The mid XVIII ${ }^{\text {th }}$ Dynasty example of an immobile chariot of six spokes (restored) sets them at hours two, four, six, eight, ten, and twelve: N. DE G. DAvies, The Tomb of Ken- 
Turning around the corner to the extreme right (west) of the north wall, the viewer immediately notices that the chariot procession still occurs (Figs. 8-13). ${ }^{61}$ Subtle differences, nevertheless, between these chariot troops and the first six are to be found, but it is the corner that forms an effective demarcation point. The last chariot on the west wall completes the scene there. That is to say, no figures overlapping the two walls were permitted. Indeed, it is hard to see how such could have been done and why would it have be even planned. Egyptian art avoided such a "modern" approach. Above these chariots is the scene of the Orontes full of killed Hittite warriors and their allies. But the frieze scene below presents interesting challenges to the researcher.

First Chariot: This group is broken. Because the second chariot shows the Hittite shield, I assume that in this case the quadrilateral shield was present, a point that is buttressed by the type of chariot: it lacks the curved side. There is no spear.

Second Chariot: The Hittite shield is evident and the common loop is also depicted. A spear is held in the right hand of the third man and so would be shown in front of the shield. (That portion of the scene is lost.) However, it appears that the complete shaft was not carved.

Third Chariot: The group is virtually the same as the preceding two. But note the presence of the common Hittite shield. In this case all three men are Hittites. No spear is present but the third man (to the rear) raises his right hand so that it is extremely flexed at the elbow. In fact, his upper arm virtually touches the left head of the horses that follow. The rendition of the reins is striking. From the point of view of the observer (right side) the forward one is incorrectly rendered because it goes behind the figure of the shieldbearer. This case presents a very good reason why we cannot overinterpret the more intricate details of such scenes. The common loop, however, is present.

Fourth Chariot: The shield is quadrilateral and the three men are Asiatics who are standing quite close together. In this case the two heads of the chariot horses face down, a rare pose that we have seen earlier. The expected loop for the reins can be seen. The chariot is non-Hittite.

Fifth Chariot: The shield is the Hittite one and the men are Hittites. There is no spear but the third man clutches with his right arm the right shoulder of his companion somewhat to the front, the charioteer. The two main men, charioteer and shieldbearer, are angled forward and so the loop of the reins, which also occurs, is moved a bit more to the front of the shield.

Sixth Chariot: Once more we see three Hittites and the Hittite shield. The reins are held differently in this case, perhaps because the third man faces backward. Here we can once more note the individual elements that could be introduced by the artist or carver. The horses' heads move down.

Seventh Chariot: The shield is quadrilateral and non-Hittites are present. The men can most probably be identified as belonging to one of the Anatolian allies. No loop or cross over of the reins is evident. One of the wheel spokes maintains the perpendicular positioning that was present earlier in the first and fourth chariots of the earlier grouping on the west wall. No spear is present but the chariot identifies its riders as non-Hittite. The horses' heads are angled higher than expected. There are eight spokes to the chariot. ${ }^{62}$

Eighth Chariot: The men are Hittites and they have their own shield. No spear can be seen and the reins, though lacking the loop, move from one hand to the other.

At this point a few summary conclusions can be deduced. The most salient characteristic of these representations is that the Hittite shield is carried by a Hittite. ${ }^{63}$ This conclusion allows us to reconstruct the manning of chariots whose men are now lost owing to time. In the first group of chariots on the west wall we therefore have: Hittites in vanguard; Asiatics (?); Hittites, Asiatics (?); Hittites; Asiatics (?).

I am assuming here that the non-Hittites were Asi-
Amun at Thebes, New York (1930) 27 and pls. XVI, XXIV. The Amunhotep II example referred to in note 58 sets the four spokes at hours three, six, nine, and twelve. One earlier case under Ahmose reveals the same situation: S. HARveY, The Cults of King Ahmose at Abydos, 531, fig. 78.

61 The number of these enemy chariots is somewhat larger than those of the Egyptians, perhaps an artistic fact that stresses the power of the enemy, but I am not tak- ing into consideration the march of the $\mathrm{Na}^{\mathrm{c}} \mathrm{arn}$. On the other hand, the war vehicles of the enemy are to be read separate from the Egyptian chariots on the west wall. The events of the attack on Ramesses' camp and the arrival of the $\mathrm{Na}^{\mathrm{c}}$ arn are two events differing in action.

62 See notes 58 and 60 above.

63 To repeat, the Hittite shield is the "figure-eight" one. 
atics and that the pattern was regular. (Instead of Asiatics for the last one can supply an Anatolian ally.) ${ }^{64}$ In the second there are: Asiatics (?) ${ }^{65}$; Hittites; Hittites; Asiatics; Hittites; Hittites; Anatolians ${ }^{66}$; Hittites.

The regularity is broken though it will return immediately afterwards. But the presence of the loop and, in fact, the varying characteristics of the reins form no standard artistic presentation. The same may be said with regard to the spear. Last but not least, the slight differences in posture, positioning of the men, and their small activities appear to be mere chance results of the predilections of the artists or, as I tend to believe, of the carvers themselves. ${ }^{67}$ Regularity occurs although these differing movements provide a strong degree of individuality and verisimilitude to the pictorial representation.
By and large no major difference can be observed between the chariots of the Egyptians and their enemies aside from the rear curve for the Hittite allies noted above. All required accoutrements for the horses are basically the same: bridle; reins (a slight difference: see below); bit; and so forth. Yet there is one striking dissimilarity. The chariots of the Egyptians always have two overlapping containers on their visible sides: one for arrows and the other for the bow. ${ }^{68}$ (N.B.: the latter logically opens to the front and it should overlap the former.) The javelin case was placed on the other side of the chariot, but this is partly confused in the work of Littauer and Crouwel who refer to a scene of Ramesses III in which quivers are set on both. ${ }^{69}$ (We cannot see if there was a javelin case here possibly owing to the
64 The Asiatics are clearly Syrians and the other groups of men must belong to the Anatolian allies of Muwatallis. The last are not more specifically subdivided. That is to say, we cannot determine from what specific country (Dardany, Lukka, and so forth) they originated.

65 This possibility can be questioned as the shield is missing. I am assuming some degree of regularity at this point. The headress of the Anatolians differs from the Hittite and Syrian ones. The protective leather helmet of the Hittites is archetypical. Covering the back and flapping down, it is easily distinguishable from the Syrians with their protective helmets moving down the brow.

The Anatolians often have a tassel (see KENDALL, The Helmets of the Warriors at Nuzi, 215-8 for North Syria) and appear to wear no helmet, but instead either have bare skulls with a hair tassel or a very small cap. The three key examples may be noted in NaviLle, Détails relevés, pl. XIII $(\mathrm{A}$ and $\mathrm{B})=$ WreszInski, Atlas II, pl. 21; and pl. XV = WRESZINSKI, Atlas II, P. 21a. NAVILLE is in error regarding this matter. From the photographs of WRESZINSKI (plus my ones made in 1982) it is clear that none of the Anatolians wore leather helmets in these scenes.

${ }^{66}$ Here, the headdress and the face overtly separate these men from the Asiatics and Hittites.

67 See the slight slips with regard to the reins. Those of the Anatolians do not run across the square or rectangular shield. The same occurs subsequently.

68 The Seti I example, which I have referred to more than once in this discussion, presents the best case owing to its details: Epigraphic Survey, The Battle Scenes of Sety I, pl. 34 . Specifically we see the bowcase overlapping the second holder, the one containing arrows. The former logically opens to the front because the right hand must be used to extract the weapon as quickly as possible. The arrows can be equally removed with a backward movement of the right arm. The latter factor is extremely crucial when dealing with bows owing to the necessity of raising it and preparing the string for the arrows.

An extremely useful representation of bowcase, arrow holder/quiver (both on the right side of the chariot) and javelin case (left side of chariot) will be found in the relief of Seti I fighting the Libyans: pl. 28 in the previous publication. Here, we see one javelin surmounted by an orb and tassels in its case and another in the body of the Libyan chief.

In the other scene of Seti I fighting the Hittites one javelin of the king has two tassels surmounting a small orb. (It penetrates the already dead Hittite in the chariot of the Hittite chieftain.) Yet the arrows, which have notched ends and a flair, have done the major work of devastation against the enemies and horses.

One further point can be mentioned here. In the Seti relief against the Hittites the enemy chariots lack the quiver. To be more specific, the sides of the chariots are depicted with only one holder and its runs up from the rear; i.e., the opening is to the front. Since the enemy carry their arrows on their backs, I assume that this is the holder for the bow.

However, the Abydos frieze is more schematic, and for this reason I assume that these details were omitted. Equally, note the avoidance of any quivers on the backs of the two enemies.

We know that the king could carry his quiver on his back: see the same two reliefs of Seti (pls. 28 and 34 in the Epigraphic Survey edition). But this is not necessarily the case in virtually all of the Kadesh depictions. Abu Simbel, for example, avoids the quiver on Ramesses' back. See notes 70-71 below for a possible explanation and one exception (Ramesseum scene of R1).

69 Wheeled Vehicles, 91 and fig. 44 (Medinet Habu temple of Ramesses III: H. H. NeLson, Medinet Habu I, Chicago 1930, pl. 71). The example could be multiplied, so I shall cite only Wreszinski, Atlas II, pls. 83-4 (Kadesh scenes of Ramesses II: L1) where there are four quivers or four javelin cases on both of the sides. Evidently, the artistic representations have to be read with a skeptical eye. This is why I have preferred to lay emphasis upon the two scenes of Seti I described previously. 
scene's orientation. $)^{70}$ In other words, the direction from which we view the chariots is composed in a symmetric fashion. Additional remarks concerning this situation will be presented in Part II of this discussion.

These patterns can be seen in the row of marching $\mathrm{Na}^{\mathrm{c}}$ arn troops on the west wall as well as those who are speeding up for battle. Moreover, the four extant Egyptian chariots at the camp are depicted in the same manner. One may quibble with regard to the lack of arrows present in the quivers. When the king is depicted in battle, however, and the Abu Simbel reliefs are useful in this context, arrows appear to have been carved in the holder lying underneath the bowcase. $^{71}$ Can we assume that the reason for their absence is due to the fact that the king spent his whole time shooting numerous arrows and there are no longer any reserve ones? ${ }^{72}$ Or is this representation mainly due to artistic convention, perhaps the desire not to spend too much time with intricate

${ }^{70}$ But I suspect the artistic convention and the regularity of depiction (i.e., the scene is standard and contains repetitive images) prevented such details from being recorded. After all, these frieze scenes do not belong to the most important episode of the battle, the king's onslaught in his chariot against the Hittites.

In the Ramesseum scene of R1 (WresZINSKI, Atlas II, pls. 96 and 96a) the side of the chariot facing the viewer has the expected bowcase and quiver. The rear side has a javelin holder, but it is situated in a position parallel to that of the bowcase and identical in shape to the quiver. Hence, can we state that the king did not carry any spears at the Battle of Kadesh? There is only one case on the left (back) side of the chariot, but it is difficult to come to a definite conclusion concerning these objects. The very detailed representations of Seti I, for example, reveal only one bowcase and the quiver that the viewer sees because the chariot is advancing to the right. But note that even here the artist has continued the angled lines demarcating the bowcase upwards so that the partly hidden javelin holder seem to be connected to it. Of course, this is not true, but merely a result of the forward placed foot of the king, which is set upon the front part of the chariot; i.e., on the chariot pole.

71 See Centre de Documentation, La bataille de Qadech, pl. 4 (upper left). This could explain the lack of a quiver on his back. N.B.: the objects are not those javelins with tassels that we have seen in the relief of Seti I fighting the Hittites; see note 68 above. On the other hand, the Ramesseum (R1: WrESZINSKI, Atlas II, pls. 96 and 96a) shows the king with his quiver on his back, and so does the Seti Libyan scene. It is evident that the artistic conventions could predominate over exactitude of event, a point that I have frequently stated in this discussion. Finally, the representation of the arrow ends may be a details? Truly, these war scenes in the bottom register that I have called a frieze lack the complexity of design that demands a high degree of accuracy and specification. That is to say, they were drawn up and carved in a pattern different from the larger depictions that were placed on the upper portions of these walls. Or perhaps the reason is two-fold: (1) the king is depicted with his arrows in his quiver since he is already shooting, whereas none of these frieze chariots have reached that stage of battle; and (2) on the march or advancing rapidly, any open quivers would be apt to loose some of their arrows. It is clear that we must view the use of chariots more carefully.

Since A. Schulman's research the use of Egyptian chariots was seen to be mobile bases for archery support. ${ }^{73}$ Yet he also stressed the shock nature of the chariot arm. The Hittite confederacy, on the other hand, had a third man to the chariot, and he is often depicted with a spear or javelin, the length of which was somewhat taller than the height of a

schematic one. Note the lack of tassels on the javelins that we have seen in one case on the Seti I relief (Libyan conflict). On the other hand, the quiver has the two orbs with two tassels apiece belonging to the body of that container.

${ }^{72}$ It is necessary to place on record a simple fact. If a man on a chariot, alone (like the king is depicted) or with a companion, stopped and spent the time tying the reins at his back before firing his arrows, this must have been done before he engaged directly with his foes. Whereas it is easy to disregard the pictorial evidence of the Pharaoh fighting alone (and stating this fact as well: see Ramesses' report in the Poem), Littauer-Crouwel argue that the charioteer would become an archer and the shieldbearer guided the reins, "which are tied around the archer's hips" (Wheeled Vehicles, 91 with fig. 44, a scene of Ramesses III referred to in note 69 above). In such cases we must assume that the attack was well planned. That is to say, the advance of the Egyptian chariotry en masse would have been in a regular and orderly manner. But this did not occur at Kadesh. The Pharaoh and his chariots were under siege and had no time for a planned counter-attack as they were caught in a desperate situation at their camp. If only for this reason I feel that the Kadesh scenes cannot be taken as archetypical representation of normal Egyptian battle preparation and maneuvers, and we cannot rely too much on Seti I's scene as providing an exact parallel to Ramesses II's depictions here.

${ }^{73}$ Classically, see his study in JARCE 2 (1963), 75-98 with pp. 85-6 in particular. SCHULMAN's subsequent work did not alter this early contention of his; see, for example, JSSEA 10 (1980), 105-53 and: Hittites, Helmets and Armana: First Hittite War, in: The Akhenaton Temple Project Vol. 2, 53-79. 
man - let us say ca. 6-7 feet or $1.85-2.15 \mathrm{~m}$ - but often shorter. ${ }^{74}$ Evidently, he was a deciding factor in clashes between two chariot arms. To put it another way, the spearman could injure, kill, or simply dislodge one of the two opposing men on an Egyptian chariot if not a horse. Against footsoldiers who carried shields (and spears as well: see the $\mathrm{Na}^{\mathrm{c}} \mathrm{arn}$ ) the third man would be equally if not more effective an opponent. Solely from the representations of the battle of Kadesh it would appear that the Hittites did not merely use their chariots as moving platforms for archery. This might appear to be confirmed by the total absence of any quivers attached to their chariots, although we must keep in mind that their quivers were placed on the backs of the archers. ${ }^{75}$

According to the Egyptian account, Ramesses led his counterattack from the camp after the Hittite chariotry had smashed the second division and had thus reached the fortified location of the Egyptians. The text of the Poem is clear, as is its repeated emphasis on chariots. Ramesses got upon his chariot and started "forth at a gallop", entering into the enemy host. This account further indicates that the enemy chariot warriors were unable to "seize their spears" (P 137), and they were unable "to shoot" (P 136). Clearly, these men did not solely operate with arrows. The Poem subsequently refers to the Hittites with bows and spears once more (P 164). Hence, even though many of the enemy chariots do not reveal a man carrying a spear, the type of warfare practiced by the chariot warriors was more effective than the Egyptians'. With these remarks in mind let us proceed with the list.

Ninth Chariot: Hittites and their shield can be seen. The reins are looped but there is no spear.

Tenth Chariot: Asiatics and a square shield occur. We now return to the expected pattern of A-B. There is no spear. The chariot is the type employed by the Hittite confederates.

Eleventh Chariot: Hittites and their shield are represented with the third man looking back. In the sixth case above it was also a Hittite who has turned his head to the rear. But in this case the man holds the upper right arm of the charioteer, clearly for support. This motion parallels the activity in the fifth chariot. There is no spear. The reins are held very far apart, and this is the first time that this occurs. There is no loop nor do the two parts of the reins connect. The horses' heads also face down. Although I do not feel that such a design is significant, I cannot but note that with this group as well as with that of chariot six there is the presence of the backward looking third man.

Twelfth Chariot: Present are the Anatolian allies and a square shield but no spear. Therefore, they form positions seven and twelve. There is no loop and the reins are held closer together than in the preceding chariot. The chariot type is once more non-Hittite.

Thirteenth Chariot: Hittites are present and so are their shields. The reins are held in the expected pattern with the loop. There is no spear.

Fourteenth Chariot: Here, the reins are held further apart and, by a mistake, that held by the right hand was not carved in front of the shield! A small loop may be seen and the junction of the reins is not carved; i.e., the one connecting the right hand with the left. There is a spearman whose weapon is nicely indicated as passing behind the right arm of the charioteer. The men are Hittites as is the shield. Noteworthy as well is the downward direction of the heads of the horses.

Fifteenth Chariot: The reins are in the normal position and the loop is present. There is no spear. The men are Hittites; their chariot is Hittite and so is the shield. The reins are held more tightly than in the preceding group.

Sixteenth Chariot: Square shield, rectangular chariot and Asiatic features of the men identify this group.

Seventeenth Chariot: The square shield, rectangular chariot, hairdress, and facial physiognomy denote the Anatolians. A spear is present and it is short and tapered much more than any other present in these scenes. It runs behind the charioteer.

Eighteenth Chariot: There are eight spokes. I assume an error. Virtually all is lost. At this point we have reached a different scene, one that moves directly up from the base of the wall register. In fact, the upper water line of the Orontes ceases. This quandary must now be resolved. First and foremost, the water line separates two independent scenes, both at the left of the west wall and also at the right

\footnotetext{
74 And the javelin or spear is shown in the hands of many (but not all) of the enemy.

${ }^{75}$ Yet the lack of extra container for arrows is significant. If these representations are true, then the Hittites
}

\footnotetext{
depended less upon archers in the chariots than the Egyptians. Nevertheless, the problems of artistic representation have to be taken into consideration, especially in these frieze representations.
} 
of the north wall. It is clear that the action in the last concerns the counter-attack of Ramesses. Captions R 24 and R 23 accompanying these broken depictions (moving to the left or eastward) present the references to two dead Hittites, one of whom was the king's brother. This is located in the middle of the advance of the Hittite chariots and at the positioning of the fifteenth chariot. There, the base line of the river moves up, eventually to surround the city of Kadesh as well as the Hittite king who will be found further along to the left. By contrast, in the earlier case (west wall) the river serves to delineate the attack of the Hittites.

But the question remains: how do these frieze chariots fit in with the totality of the action? This query is, in fact, the one that Naville made in 1930; namely, "it is no longer possible to follow the chronological order of events" in the lowermost scene. ${ }^{76}$ His conclusion was that the "sculptor must have disregarded it, contenting himself to carve the scenes in honour of the king and his Egyptian army".

Yet we have noted the focus of activity at the extreme left of the west wall, and that the action appears to continue onwards to the north wall. If we continue the motion, then we are forced back to the Hittite camp with King Muwatallis shown avoiding a personal commitment. But he later sent out his chariots to do battle. Exactly when in time do the depictions on the north wall refer? The upper scenes reveal the carnage caused by the king's ferocious and successful counter-attack and at the same time (further on to the left) show the Hittites fallen into the Orontes with the luckless king of Aleppo being rescued, and further to the left we see the Hittite king facing backwards, refusing to lead his troops for whatever reason. With these factors in mind, I feel that the temporal framework can be carefully reconstructed.

The chariots that were carved just above the base on the right hand side of the north wall indicate the second plan of Muwatallis in action. Above is the defeat of the Hittites on the battlefield near the Orontes. Therefore, the phase of battle must be after Ramesses sped into battle and caused the advancing chariots to be smashed, many of which as well as men, horses, and equipment, ended in the river. This is explicitly indicated in the Poem (P 143ff.). To quote Gardiner, "But the wretched chief of Khatti stood in the midst of his infantry and chariotry looking at the fighting of His Majesty alone by himself, ... turning back, shrinking and afraid". ${ }^{77}$ We have reached the point when the quoted 2,500 Hittite chariots failed in their surprise movement and after the Egyptian king had successfully pushed them back to the Orontes. ${ }^{78}$ Then the Poem tells us that Muwatallis sent an additional 1,000 chariots to the fore, this time led by the most important princes of his coalition. They included Anatolian warriors such as those from Arzawa, Lukka, Dardany, and the like, as well as North Syrian allies from Carchemish and Aleppo. Brothers of the Hittite king are also mentioned (P 152). Hence, this chariot division must be the one indicated at the base of the north wall.

The Egyptian artists have, in fact, separated the frieze scene on the north wall from the west, but in this case the striking parallelism of depiction was also considered. That is to say, the pictorial aspects of the entire battle, a section of Phase I and II to be precise, are not that different. This conclusion is reinforced by the second curving of the water. Just to the right of the hapless king of Aleppo this upward movement of the waters can be seen. This differs from the previous one in one respect. The left side curves further upwards than the right and becomes a perpendicular line. (In both cases watermarks cease a bit after the curve commences.)

There are also two horizontal water bands that refer to the same river, the Orontes. The upper one is filled with the dead or wounded Hittites and their allies. The lower is merely an empty river. Therefore, the former belongs to the action of Phase II whereas the latter serves as the base line of the register. In essence, it demarcates the east side of the river Orontes.

By this means we can now view the Hittite king at the situation of sending his second wave of elite chariot troops forward.

Nineteenth Chariot: The men are Hittites and so carry their typical shields and have their own type of chariot. A poorly placed spear is present: it runs behind the shieldbearer. No reins have been carved. The chariot is crossing the Orontes. We are thus at the definitive second stage of the battle.

Twentieth Chariot: The heads of the horses are
76 Détails relevés, 17 . This situation was discussed earlier.

77 The Kadesh Inscriptions, 10.

78 I will discuss the numbers of the enemy chariots at a later date. The Classical study remains that of DELBRÜCK, Numbers in History, London 1913; see also GARDINER, The Kadesh Inscriptions, 65. 
directed upward as if the chariot is at the point of combat. This minor trait may indicate that the artists set this group of warriors at the fore of a different phase of battle. However, the horses themselves are in their normal frontward rearing position. The men are Asiatics, their shield is rectangular, and so is the chariot. Note, however, that the reins have not been carved. Naville indicates that part of the portion held by the right hand was, but this is not so. No spear is present.

Twenty-first Chariot: The men must be Hittite as their shield is present and the chariot itself is a Hittite one.

Twenty-second Chariot: The men, chariot, and shield indicate their Hittite origin. The rear man holds the right arm of the charioteer; no spear is carved. The loop of the reins is present.

Twenty-third Chariot: Here we meet Hittites, their shield, and their chariot once more. The third man (to the rear) is holding a short spear. It is raised as if ready to throw. This is the only time that this occurs in these bottom scenes.

Twenty-fourth Chariot: Three Asiatics are in their chariot; no spear is included. The third man looks back, an unusual position for the non-Hittite. As a rule it is the Hittites who are depicted with one man looking backward. The reins are held normally but there is no spear.

Twenty-fifth Chariot: The Anatolian allies are present and their shield and chariot as well. The reins are carved normally with the loop. The third man looks behind toward the elite guard of his king. $\mathrm{He}$ is bent backward and his companion, the charioteer, is pulling the reins to speed up the horses. This activity seems to indicate that the chariot has just begun to move away.

The bottom series of chariots ends here. To the left (east) on the north wall a different scene is carved. It runs from the base line of the water upwards and is enclosed by a second register. Here, one sees more the elite or thr warriors. It is useful to stop at this point because we can summarize the details of this extended frieze of Hittite troops.

By and large, the minor differences specified in our detailed commentary are individualistic and cannot be employed to derive any specific system of presentation. There are Asiatics, Anatolians, and Hittites. The latter outnumber the former two combined. This difference is marked, but such minor details as the positioning of the horses' heads, the direction of the angle of the spokes, and the rearward facing third man are inconsequential. Once more, I feel that these differences were left up to the sculptor or per- haps were caused by a master artist/supervisor who oversaw the carving. At the end, except for the second chariot of the enemy and one with the Anatolian allies, all of them, which are drawn with spears, contain Hittites. This minor theme, however, should not be taken to heart. But it is useful to compare these chariots with others also drawn at Abydos.

Beyond or behind the personal bodyguard of king Muwatallis are a series of advancing enemy chariots (Figs. 14, 15). This time they march up and over the enemy station, separate from it by a graduating curved line. Terrain is thus indicated, and we are still in Phase II of the pictorial representation. Here we can see that the presumed regularity of the frieze depiction is not followed. For example, the first series of aligned single-file chariots reveals an interesting situation. The enemies are going to meet the Egyptian king in combat. They move up and around the positioned elite warriors into the right. Here, a question similar to that posed earlier occurs: what phase of the battle is indicated? As they are connected with the king and must cross the Orontes, which is located to the right as well, I suspect that we witness the earlier charge of the Hittites against Ramesses before their king saw the failure at the Egyptian camp. Otherwise, we are left with the problem of the bottom frieze of chariots on the north wall. Since there is a base line separation, albeit curved, I feel that this section of the scene must refer to a different time in the battle. It might be of some importance to note that none of the extant soldiers in the chariots are Anatolians. Only Hittites and Syrians are present. If this somewhat meager data is taken to heart, this might indicate that Muwatallis only threw his Anatolian allies on chariots into battle in the later phase of battle. After all, as we have seen earlier, the account of the Poem indicates that these men did participate after the slaughter up to and at the Orontes.

Four registers of upward moving chariots can be detected on what remains of the wall. Once more water separates them from the scene further to the right (Phase II in the battle). In this case, because the Hittite chariots are attacking we have to reverse our direction in order to ascertain the correct geographical direction. First, the location is on the west of the river Orontes. That is to say, directly opposite the city of Kadesh. Second, the chariots are moving against the Egyptians. This implies that their leftright direction is actually east west. The water is nothing more than the river, and so has to be viewed in a direction opposed to our north-south cardinal points. Reading from the left to the right the following may be seen. 


\section{Register I}

First Chariot: The third man is just getting into the chariot. All three men are Hittites. The reins of the charioteer are incomplete and, in fact, the one to the rear of the viewer (left side) runs behind the shieldbearer. This is a clear error. It is very useful to see that the climbing third man carries the spear in his right hand. The reins are not completely carved. The right hand side of them, which is always to the viewer, is not present. Instead, the left side runs backward to the shieldbearer and then stops as if it wound around that man. (Of course, this is not a correct interpretation of the actual scene.) The charioteer appears to be holding the rein by his left hand while his right hand is raised and at the elbow bent, as if he had a short spear in his hand. See, for example, the third man in chariot twenty-two above. This, however, must remain unclear, as it is always the third man in the rear who is associated with that weapon.

Second Chariot: The three Hittites are in their vehicle and the normal shield and chariot are depicted. No spear can be seen. A portion of the scene has fallen away between the time that Naville copied these depictions and when Wreszinski took his photographs, but the original Hittite shield was present. The heads of the horses face down. The reins appear to be normal but if there was a loop, as I believe, it has been lost.

Third Chariot: We are now moving up the slope. Three Asiatics in a quadrilateral-shaped chariot are present. But the shield is a Hittite one. I cannot but assume that there is an error here. There is no spear but the charioteer holds the reins in a forward position by his right and left hand. Noteworthy is the artistic rendering: the left hand is shown in the correct fashion as is the right. The former reveals the palm, and the fingers are carefully executed whereas the right shows the back of the hand. In this case it is evident that fast motion is recorded.

Fourth Chariot: Once more there are Hittites with their shield and chariot. No spear is drawn, and the left hand of the charioteer is the one holding the reins.

Fifth Chariot: Three Hittites with a square shield and a rectangular chariot are depicted. Here as well I see an error in execution. The rear man holds onto the right middle arm of the charioteer, a position that we have noted earlier. The men are slightly angled forward, again to indicate the velocity of their movement. The charioteer holds the reins in both hands but the right one is almost vertical. It runs directly downward from the shoulder. There is no spear.
Sixth Chariot: The men ought to be Hittites as the chariot is a Hittite one. Little else remains.

Seventh Chariot: The chariot is a Hittite one.

The four remaining chariots are not worthwhile to analyze owing to the fragmentary nature of the wall at this point.

\section{Register II}

First Chariot: The first group of men are already in their chariot. The men are Hittites and so are their shield and chariot. The reins are held by the middle man, the charioteer, but there is neither a loop nor a crossing part of the reins.

Second Chariot: Here we have three Hittites once more and their shield indicates this as well. However, the chariot is non- Hittite. The third man flexes his right arm in order to throw a spear but none is carved. Naville has indicated a mar in the stone above the hand by means of a few scratch lines but not even a short spear can be seen.

Third Chariot: The men are bent forward very strongly. There is no loop in the reins but the charioteer holds both sides. All three key indications indicate that the Hittites are present. The spear is absent.

Fourth Chariot: Here, virtually all is lost.

\section{Register III}

First Chariot: Asiatics with their square-type shield and their chariot are denoted. The movement is more relaxed if only because the men are basically erect in posture. The charioteer is slightly bent forward, as is to be expected, and he holds the reins separately. Noteworthy is the vertically oriented spokes: possibly seven or eight.

Second Chariot: This one is in the Hittite style. Nothing more can be determined.

\section{Register IV}

First Chariot: Only the vertically directed spoke is a demarcating sign. There are eight spokes. From this fragmentary group of warriors some key points may be discerned. The virtually lack of spears is perhaps noteworthy. After all, the leftmost portion of these registers indicates that we are witnessing just the commencement of the chariot movement. It is only when a warrior approaches very closely to his opponent that the spearthrower must prepare his movement of attack. On the other hand, the apparent mistakes in carving cannot be ignored. The presence of Hittite warriors in a non-Hittite chariot, such as with the second group in register two as well as the Asiatics in the first register having a Hittite shield indicate to me a more slip-shod presentation than seen previously. But the minor variants of 
action seem to reveal the same individuality as with the lengthy frieze at the bottom of the scenes of the west and the right side of the north wall even though no regularity can be observed.

\section{II.}

In general, these chariot representations form a homogeneous subsystem within the detailed war scenes at Abydos. That they do elsewhere is self-evident, but I have preferred to concentrate upon one temple in order to deduce their outlook more strictly. The paucity of spears is one clear indication of communality. We are, in fact, at a disadvantage in this respect because it is crucial to determine how, exactly, these weapons were handled and precisely how long were they. For example, the normal way of holding spears is with the "under-grip", but the thrust is not very strong and often the direction of throwing is not accurate. Hans Delbrück, who summarizes the use of such weapons held by footsoldiers, points out that "since the lower arm and the hand must take an unnatural, almost vertical position" when throwing, the effect is often muted. ${ }^{79}$ "This thrust", he says, "really has its full effect only when made downward from above", a situation that fits the position of the third man on the chariot. Namely, that he operated from a mobile platform against footsoldiers and also against advancing chariots. In the case of the latter the horses would be the easiest to incapacitate. As with infantry, the spearthrower needed no shield. Indeed, it would be virtually impossible for him to carry one owing to the exigencies in manipulating that object.

But it is noteworthy that the spearmen, when they are depicted in these scenes, appear in a small group right at the point of their encounter with the Egyptians. We have seen that the first chariot of the advancing Hittite onslaught shows in great detail these weapons. Commencing from the Orontes, the first, second, and fifth chariots definitely have them. Subsequently in the frieze they turn up in position

79 H. Delbrück, Warfare in Antiquity, Walter J. Renfroe, JR., trs., Lincoln-London 1990, 276.

${ }_{80}$ But the Anatolians all look alike. Let us remember, however, that the colors are lost.

${ }^{81}$ And the system of cheek straps, bit, etc., for the Hittite horses differed from the Egyptian. There are still two cheekpieces but the arrangement is somewhat different. For example, two straps run over the head, and the lower band tends to flare out under the chin. In the Seti I scene that I have frequently referred to the detail- eight, twenty, twenty-three (possibly), twenty-five (re-emergence of the Orontes), and a short spear can be seen thereafter but once (number twentynine). Only the last man mounting his chariot in register I of the later scene reveals his spear; it is clearly not in action. Hence, their near absence in this section may be connected to the specific time in which these chariots were meant to have been in action. The actual melee of warfare is not present.

The difference in physiognomy well reflects the specific details that the artists utilized in war scenes. ${ }^{80}$ Likewise, the specific two types of chariots employed as well as their coincidence with two types of shields. ${ }^{81}$ Here, the difference is reduced from three ethnic groups (Hittites, Asiatics, and Anatolians) to two. But any specific means of demarcating the warriors from Lukka, for example, from those of Dardany or Arzawa is impossible to determine. Nevertheless, the Egyptian chariots differ from the "pure" Hittites ones. The latter have sides that are less curved than the former. To be more specific, the rear angle of the side of an Egyptian chariot projects further out at the top than the Hittite one. As a result, the curve and the obtuse angle which continue down to the center of the wheel spokes are more sharply delineated that those on the Hittites' vehicles. ${ }^{82}$ It is also the case that the side on Egyptian chariots appear in these reliefs to be slightly taller than their counterparts. We have further mentioned the presence of the quivers and bowcases on the Egyptian chariots. Those of the opponent are specific in their absence of such necessary accoutrements. This may be the result of two differing approaches to chariot warfare. Namely, that the Egyptians relied upon their second man as an archer, the first being, of course, the charioteer. If in a still position, the charioteer would fire the arrows. On the contrary, the Hittites operated differently. They had the advantage in positioning a third man in the chariot who was a spear thrower. ${ }^{83}$ As a result, while the charioteer did ing allows us to see these contrasts. On the other hand, the Hittite system indicated there seems to differ slightly from that rendered in the chariot frieze.

${ }^{82}$ See notes 52 and 56 above for a somewhat more detailed description of the Hittite chariot in a key relief of Seti I.

${ }^{83}$ The larger the spear the less useful is the shield: DELBRÜCK, Warfare in Antiquity, 394-5 and Medieval Warfare, Walter J. Renfroe, trs., Lincoln-London 1990, 651 (referring to the Burgundian wars of Charles the Bold against the Swiss and other battles of the Swiss). 
his business, there was a further man available who acted as the protector, the shieldbearer.

This difference meant for a different form of fighting. The Egyptian one being straightforward, we can turn to the Hittite system. With the spearman somewhat in the rear, and so partly protected by his two companions, the thrust of his weapon was crucial. This different emphasis of warfare meant that the Hittite chariot onslaught encompassed a goal different from the Egyptian one. Whereas the former aimed at disabling either footsoldiers or chariot opponents, and even horses, the Hittite organization, which naturally was directed to the same goals, nonetheless had a greater thrust close up. Archers can perform their activities somewhat removed from a face-to-face (or chariot to chariot) encounter. Spearthrowers, on the other hand, need to be relatively close to their enemy in order to inflict damage. In addition, spears are more effective in disabling horses than arrows.

An encounter between these two types of chariots without any much infantry present leads to interesting conclusions. It is true that in scenes of carnage, one can see some spears in the bodies of dead Hittites. This case, for example, is located in the attack of Seti I against the Libyans as well as the one directed against the Hittites. But at Abu Simbel we see the other possibility. Behind the Pharaoh are two dead Hittites in their chariot. (The representation of the chariot leaves no doubt that it is the enemies who have been killed.) They have been killed by being transfixed by arrows. In the same scene at Luxor (the L1 version), on the other hand, arrows have entered into the bodies of the luckless foe. ${ }^{84}$ This is also true with regard to the two Ramesseum exemplars, R1 and R2, and in the latter case smaller arrows are evident. ${ }^{85}$ It is fair to say that in all the depictions of actual carnage relating to the battle of Kadesh, only arrows are indicated as the means of killing the men in Hittite chariots. After all, is this not what the superhuman depiction of the king indicates? He charges forward, alone, with his bow taught and an arrow ready to let fly. Owing to the complexities of this situation, I shall leave further discussion to the end of this study.
With archers, whether on foot or in a chariot, distance is less significant. Owing to this factor, the Egyptian chariotry were aimed at felling horses, ${ }^{86}$ chariot men, or footsoldiers at a point not necessarily in the field of battle. Following Schulman and others, we can conclude that a massive chariot maneuver, such as what Muwatallis ordered in the latter part of the day, was not a tactic that the Egyptians were used to. ${ }^{87}$ Indeed, their chariotry would have been uncomfortable following such a policy. Unfortunately, we lack any ancient Egyptian manuals that tell us how the Egyptian army practiced or was expected to fight. The so-called "Poem on the King's Chariot" reveals absolutely nothing with regard to the contemporary mores of this elite division. ${ }^{88}$ If the representations of the $\mathrm{Na}^{\mathrm{C}}$ arn are correct, then the infantry accompanying the chariotry most probably were expected to engage with the footsoldiers of the enemy face to face. Their short weapons (axes and little sickle swords) indicates this. The accompanying chariotry, then performed the archer component, and naturally served as a means of dispersing the enemy infantry if not acting as a mopping up operation.

But from the scenes of chariotry so far covered, the artists/carvers could make errors, and these cannot be disregarded. At Abu Simbel, I believe that they are more frequent than at Abydos. Nevertheless, I still feel that it is the individual small idiosyncrasies that can tell us more. As an example, let me return to the attempt (or otherwise) of order in the chariot representations. With regard to the Egyptian mounted forces on the southern portion of the west wall, we have seen that some type of A-B pattern was intended. Whether this simple artistic convention was "betrayed" by the presence of different workers performing their tasks next to one another on the same wall can be left aside. If we turn to the frieze scene of the first major portion of Hittite chariots, no such regularity can be discerned, partial or otherwise. This is what leads me to suspect that a general order was given by the master or masters to their underlings, one that was not focused upon total conformity to a rule or pattern, but one that allowed a degree of individuality to enter into the

${ }^{84}$ WresZINSKI, Atlas II, pls. 83-4.

85 Ibid., pls. 96-96a (R1) and 100-01 (R2).

86 These animals were and are the likely target, if only owing to their size (in comparison to men) and importance (locomotion). One the horses were disabled,

then the enemies could be picked off. The battle of Agincourt provides an excellent case.

87 For Schulman's research, see note 73 above.

88 Most recently, see ScHulman, JSSEA 16 (1986), 19-35 and 39-49. 
final product. Even such things as minor as the spokes of the chariots or the direction of the heads of horses shows irregularities. In the first case, however, we can argue that when the wheel spokes are not aligned at a ninety-degree to the base line because they are in motion. This may be a general rule, but it is not quite that accurate. In another scene at Abydos (Phase III) we see the captured booty and enemy brought back into the presence of Pharaoh. Here, the chariots must be moving. Yet note that in the three extant cases the axis of two of the spokes is perpendicular to the ground. Does this indicate a very reduced movement? This scene is also useful to discuss because the horses heads vary. The regular position (once) as well as the downward directed one (twice) occur. And, undoubtedly more important, the wheels of these three Hittite chariots have six and eight spokes. Earlier I felt that these few cases could be best explained as carvers' errors. That I still maintain. But these eight spokes might indicate that they belonged to the more important warriors who were present on the side of the Hittites if not to the leaders of the key enemy divisions.

This analysis has concentrated mainly upon the chariot section of the Abydene Kadesh reliefs. I believe that the intricate and detailed nature of the entire series of Kadesh depictions deserves far more of a study than that presented here. Yet by choosing one temple and one group of reliefs from that religious building, we are more able to see the capabilities and expertise of the Egyptian artists. At the same time, although this extended frieze is simple in orientation, it is more complex than one may at first believe. Movement upward is clearly indicated at certain (but not all) sectors of the composition. Then too, the careful interplay of forward march (west wall, south end) to battle is recorded. Change through movement of the separate chariots components provides the basis for our historical reconstruction. In this case the $\mathrm{Na}^{\mathrm{c}}$ arn are advancing to support the king and then are charging. The presence of the guard of the king, with Egyptians and in the center, the Sherden, is also well designed. Here, we are required to focus our attention to the scene of the spies above. Leftwards, or to the direction of the north wall may be found the failure of the Hittites to invade the camp of Ramesses. With the presence of the Orontes, which does not completely divide the action into two symmetric halves, we move to a different historical frame.

The chariots representations still pose difficulties of interpretation for modern scholars. Granted that the scenes at Kadesh tend to present a generalized picture and lack many details necessary for our understanding of the object, additional non-pictorial evidence aids in reconstructing the entire object. Early in the history of Egyptology it was noted that six spokes to a wheel was the standard. ${ }^{89}$ True, eight spokes have been found, but the evidence for this is rare and confined to the late Eighteenth Dynasty. (The interpretation is somewhat questionable as well.) The axle was in the rear and on the sides were the bowcases and the quivers. I am assuming that scenes in which the chariots have quivers on both sides of the chariot when viewed from one direction may not always reflect the truth. On the other hand, with one bow the case it would have to be located at the same side where the man's right arm was.

This then leads us to the problem associated with direction in art. At Abu Simbel, to take a noteworthy case in point, the $\mathrm{Na}^{\mathrm{c}}$ arn advance from the left to the right. In many cases we see the charioteer holding the reins by means of his left hand. The movement is therefore relatively slow and peaceful. In his right hand one charioteer has a short stick that is not notched at the end. ${ }^{90}$ More importantly, the bowcase and quiver face us and overlap in the accepted pattern. Now the shieldbearer, who faces right, is viewed from the inside. I.e., we see him holding the shield from the right and the strap which he holds is depicted. This is in contradiction to the frieze of chariots at Abydos. If the Egyptian man protects his charioteer from the right, the leftward moving $\mathrm{Na}^{\mathrm{C}}$ arn chariots fit this pattern perfectly. However, the rightward moving chariots of the Hittites do not, because the shieldbearer, placed to the charioteer's left, holds the shield in a direction so that we see its outside and not its inside. This reflects the following system at Abydos:

\section{Right Hand Side (Direction Left)}

1. Egyptian troops ( $\left.\mathrm{Na}^{\mathrm{c}} \mathrm{arn}\right)$.

2. Shieldbearer is to the rear or on the right.

3. Shieldbearer holds the protective armament with his right hand.

4. Outside of shield is seen.

\footnotetext{
${ }^{89}$ See the basic sources covered in notes 56 and 58 above.

${ }^{90}$ Centre de Documentation, La bataille de Qadech, pl. 4,
}

bottom left corner. The sticks were used to beat the horses. 


\section{Left Hand Side (Direction Right)}

1. Hittite troops.

2. Shieldbearer is to the rear or on the left.

3. Shieldbearer holds the protective armament with his left hand

4. Outside of shield is seen.

At Abu Simbel the case is closely parallel but not identical to the second:

Left Hand Side (Direction Right)

1. Egyptian troops $\left(\mathrm{Na}^{\mathrm{c}} \mathrm{arn}\right)$.

2. Shieldbearer is to the rear or on the left.

3. Shieldbearer holds the protective armament with his left hand.

4. Inside of shield is seen.

It is self-evident that the artistic preference has overridden the truth, and this has to do with the requirements of Egyptian art. The reason is simple: "orientation to the right is dominant in Egyptian art" ${ }^{91}$ It is only with left-facing figures that some compromise had to take place. Hence, we can see that the shieldbearer stood to the left of the charioteer. He protected his partner with his shield that was held in the left hand. (See additional comments on this situation below.) He could not have used his right hand for the most simple of reasons. There was no room to manipulate the right hand and shield if both were required. If it is argued that the shieldbearer stood to the right of the archer there would have been a major problem for the charioteer. The latter man also served as an archer. In order to raise a bow and to take up the arrows from a quiver, he would have then used his left hand. This is impossible.

If the following argument is too simplistic for those accustomed to archery, then they can disregard these comments. For some Egyptologists, however, the following remarks are probably necessary. To operate a bow for a right-handed man, it is necessary to hold the weapon in the left hand. The string has to be pulled back and the arrow, taken by the right hand, is placed in a horizontal position with the bowstring serving as the rear stop for the arrow. The arrow is then initially carefully placed over the left hand and then set more correctly at the back. All of this requires the maneuverability of a powerful arm, the left one. This cannot be done with the left hand feeding arrows to the bow.

The right hand side of the chariots is where the quiver and the bowcase were placed. This is keenly noted in the examples at Abydos where the Egyptian troops and their chariots are at rest and face right, but ready to be utilized for the forthcoming onslaught of the Egyptian army. The system is: charioteer right, shieldbearer left. This leads to the "logical" artistic bifurcation of the two directions, left facing and right facing:

Right facing: charioteer is in front; shieldbearer is in rear. Left facing: charioteer is in rear; shieldbearer is in front.

Note the alteration of positions owing to the Egyptian demands of representation, even though the second representation is a false one. Given the above analysis, then the following results:

Right facing: charioteer is protected by the shieldbearer who holds the shield with his left hand. We should see, at least partially, the inside of that object.

Left Facing: charioteer is protected by the shieldbearer who holds the shield with his left hand. We should see the outside of that object, and that, in fact, is the case.

Parallelism of intent in the frieze scene at Abydos (and elsewhere) prohibits such a totally accurate rendition. Of course, so does the artistic convention employed. The Hittites, advancing to the right, ought to have been depicted with at least part of the inside of their shields visible but this was not done because of the demands for a symmetric presentation. But the shieldbearer is to the left, as expected. As for the hands of that man, they are correctly positioned: the left holds the protective implement. Naturally, this means that the entire representation of leftward advancing Egyptian support troops $\left(\mathrm{Na}^{\mathrm{C}} \mathrm{arn}\right)$ is not correct from a "rational" viewpoint. But this should not disturb us, once we keep in mind the orientation and the requirements of ancient Egyptian artistic representation.

There is a section subscene at Abydos and Abu Simbel that can provide some helpful reflections upon the two directions of movement. We have already noted that the Sherden guards show the exterior of their shields whether marching to the left or two the right. Abu Simbel, on the other hand, presents a diametrically reverse vantage point. Once again, we see the insides of the shields rather than the outsides. At Abydos those men marching left carry their shields with the left hands and those marching right have them born by their right hands. The Egyptians to the right and behind these merce-

91 RoBIns, Proportion and Style, 21. 
naries are depicted similarly. They have their weapons in the right hand as do the Sherden and their shields are supported by the left hand. At the left of center the Egyptians move forward to the right with their weapons in the left hand and their shields on the right. (We know that the shield was always held by the left hand in the hoplite army of Greece and later by the Roman legions.) Because the right-facing men are oriented correctly, following the primal point of view we have to accept the conclusion that at least here - when a guard of soldiers is represented who are not fighting - the shield was carried in the right hand.

One further point may be elucidated. In the depictions of the Hittite chariots moving right, we see all three men. The spearman is in the middle but always to the back. Clearly, the limitation of space on the chariot floor led to the situation that he must perform his activities - which required a large degree of movement - somewhat freer than the forward two men. In addition, the charioteer is always carved somewhat to the rear of the shieldbearer. Is this correct? Such a question is important if only because Egyptian art demanded that with a couple, the person placed in front of the other takes precedence. ${ }^{92}$ With a sitting pair of man and wife facing right, the man is to the right, the crucial location, and depicted in front of the woman. In these battle scenes, on the other hand, the man to the viewer's rear is always the shieldbearer who, as we have seen, was to the left of the charioteer. Yet it was the charioteer who later turned himself into an archer. He and he alone performed the necessary carnage on the battlefield. Pharaoh, after all, attacks the enemy with his arrows. I prefer to interpret these scenes of three partially overlapping men as a reflection of the desire to record the purpose of all the men: charioteer, spearman, and shieldbearer.

Let us now turn to the use of the spears or javelins. In the two scenes of Seti I, as I have remarked in Part $I$, the scenes of carnage show the key enemies killed by long narrow objects which are spears. Yet since the king is shooting arrows, I cannot but conclude that those weapons must have been present and apparently used first.

92 Ibid., 19-21.

93 See note 52 above.

94 The Organisation of the Hittite Military, 148.

95 Ibid., 149. He also maintained that "Perhaps one of the duties of the third man was to carry this weapon".
The use of the chariots by the Hittites deserves also some amplification, especially in light of Richard Beal's able study on their military. He correctly notes that in the battle relief of Seti I against the Hittites, the enemy chariot, also of six spokes, carries only two men, the second of which is portrayed having a bow. ${ }^{93}$ Was this a correct rendition? We know from the war records of Ramesses II as well as the pictorial representations accompanying the Kadesh battle that there were three men to a Hittite chariot. Indeed, this is a staple of the scholarly literature. We have also seen the importance of the spear in this arm of the military. Beal felt that the Hittite archer "wore his quiver slung over his back", and a bowcase was probably attached to the cab. ${ }^{94}$ (See below for a more detailed analysis of this situation.) Beal further indicated that their spears were around seven to eight feet long. ${ }^{95}$ However, the Abydos reliefs contradict this supposition. I would place the spear ca. 6-7 feet long. Both hands at a downward angle could hold it without too much wobbling. Its accuracy, to repeat my earlier comments, was aided by the downward motion of the attacker.

Such spearmen must have aimed either at the horses or at the foes. The downward effect of the weapon favored the former use, and a thrust directed at the torso (and not at the face which Littauer and Crouwel believe) ${ }^{96}$ of an enemy could have been accomplished without too much difficulty. In this case, however, the motion would be near horizontal to the chariot floor or the ground, and so it would not be as effective as the first movement. Most certainly, as Beal noticed, the under grip was employed. ${ }^{97}$

In essence, then, we have two opposed methods of chariot warfare. The problem with the Hittite representations at Abydos and elsewhere is connected to the scene of Seti I. The key issue is: how much can we trust the pictorial evidence? I have stated in the last paragraph that the chariot scene of one Hittite chariot with two men was understood by Beal to be factual, and because of this he assumed that a change in military support had taken place between the reign of Seti I and his son Ramesses II. ${ }^{98}$ But was such the case? Not many

\footnotetext{
96 Wheeled Vehicles, 92. I feel that the archers aimed mainly at the horses; see note 85 .

97 The Organisation of the Hittite Military, 149.

98 Ibid., 149.
} 
years had elapsed between the encounter of Seti against the Hittites and that of Ramesses at Kadesh. Can we allow a total reorganization of the Hittite chariot to have occurred during that relatively short period of time? If this is accepted, then we must maintain that the allies of the Hittites, at least at Kadesh, had also effected such a switch. The latter I find somewhat troubling. Indeed, the common representation of all of the Hittite chariotry - allied or not - fits with the generalized artistic representation discussed here. As we have seen, not that much differentiation can be noted.

The use of armor by the Hittites, a fact stressed by Beal, is pretty well ignored by the artists at Abydos, or at least in those scenes that are preserved. ${ }^{99}$ The Egyptian reliefs show the Hittites "wearing a garment reaching down as far as their elbows and ankles". ${ }^{100}$ To Beal, the colored strips on these garments indicated armor. Among the chariot crew, on the other hand, there is a band around the waist of many of the Hittite chariot crews. This is not always drawn in the bottom frieze, a situation that we have come to expect. But when done, all three contingents (Hittites, Asiatics, and Anatolians) are shown this way. Following a cautious qualification by Beal, I prefer to regard these chariot warriors as wearing armor. ${ }^{101}$ Most certainly, the long garments referred to by him can be seen on the guard of thr's surrounding Muwatallis. Others may be noted in the scene of Phase III: the reception of the defeated enemy. There, two types of apparel are present although once more this is a generality dependent upon the reliefs. They may be partly inaccurate here as well. Indeed, their garments have folds, and I assume that they were armored. Spears and armor go together on footsoldiers, but we must remember that chariot men were and are different. I do not see any scale armor protecting the horses as advocated by Beal, but in this case perhaps the native artistic conventions of Egypt took over. ${ }^{102}$

Let us also keep in mind that these chariots did not serve the same purpose as our modern tanks. They were employed for rapid movement to and from the battlefield. For the Egyptians, it was necessary to convey their chariots to the fight and then switch to archery. On the contrary, the Hittites had the extra man who served first as a spearman, but

\footnotetext{
99 Ibid., 150-3; see as well KENDALL, The Helmets of the Warriors at Nuzi, 201-31.

100 Ibid., 150
}

who later could be an archer whose quiver was on his back. This may be why we do not see quivers on the Hittite chariots. They were not necessary. The spearman, after throwing his weapon, could then use his arrows for war, and his quiver would have been attached to his body, a point partly noted by Beal. Indeed, I see no reason why that man could not have jumped down from his chariot (which would have stopped) and then engage with the enemy on foot, provided that he could quickly reenter his vehicle, which would then speed away. (We can see here once more the basic use of the chariot: quick movement.) On the other hand, the spearman would have remained "on board", so to speak, and use his arrows similar to that of the Egyptians.

But the Seti I scene reveals that the chief Hittite's chariot had a bowcase, and Ramesses II's reliefs show it as well. Perhaps these details are accurate. (At Abydos we see the Muwatallis' bow case to the left; however, the figure is facing left and the chariot is royal.) This implies that those advancing Hittite chariots in the frieze ought to have had bowcases oriented to the viewer. However, they are not present. Hence, we are faced with an anomaly. Do we consider the spearman to be archers as well, a point that I have argued above? Whatever is our interpretation, I still feel that the quiver was not regularly placed upon the Hittite chariot. This position supports Beal's other contention that a Hittite archer wore his quiver on his back.

But the anomaly can be also explained by noting where, and with whom, were these visible bowcases. Beal himself stressed its presence only with the king. The Seti I example reveals only two Hittite men to the chariot. Rather then seeing a development in Hittite armaments from the reign of Seti I to that of Ramesses II, can we maintain that either: (1) depictions of the Hittite king's chariot and personnel were expressly copied from the Egyptian model; or (2) that the Hittite king's chariot served only for two men, king and shieldbearer? I do not think that an answer can be given that resolves this dilemma. At Abydos, Muwatallis' chariot is drawn with more specific detail than his other chariots. In fact, we can observe the slight but nonetheless important differences between the side of Ramesses' chariot and that of his opponent's.

\footnotetext{
101 Ibid., 150 with note 547.

102 See Kendall, The Helmets of the Warriors at Nuzi, 205-06.
} 
Before I acquit myself of this analysis, one final point can be covered, and that is the situation of the reins. ${ }^{103}$ From the decoration on the chariot box of Thutmose IV we see four reins. Was this the case of the Egyptians at the battle of Kadesh? Seti I, in the two key scenes that I have referred to in the footnotes, shows us four reins. ${ }^{104}$ At Abydos the frieze scenes appear to represent two or four reins, but these are, of course, schematic representations and lack the fine clarity of detail in scenes with the Pharaoh. Other Kadesh representations appear to indicate a two-rein situation, but they are harder to interpret. Nonetheless, as we have noted, in the frieze scene at Abydos all too often the reins were not completely carved or they were left off. Hence, the veracity of these depictions can be questioned, especially when we realize that to carve four reins was considerably more difficult to execute than two, and from the direction of the viewer, the rear pair could be drawn parallel to that in the front. ${ }^{105}$ One case might clinch the argument because we can see that a charioteer holds two reins in his left hand that run behind the fist. ${ }^{106}$ In actuality, however, one rein comes from the right hand and the other from the left. We must therefore conclude that either the frieze scenes are too standard and relatively too small to enable the execution of fine details, or that the reins are simply depicted by thin incised lines and not as thicker cords bounded by two lines. ${ }^{107}$

By and large accuracy of representation remains our key dilemma in assessing the Abydos reliefs and, for that matter, all of the other ones associated with Egyptian warfare. The question of protective skullcaps worn by the Egyptians and their opponents, for example, has not been covered here. These fine points parallel in difficulty many of the others covered above: horses' heads; foot movements; presence of spears; use of the reins. All in all, I have preferred to restrict myself to one small portion of the Abydos Kadesh reliefs in order to highlight the complex yet interesting idiosyncrasies of the artists and carvers. In addition, I felt it was worthwhile to leave off any analysis of the gigantic scenes above the bottom registers that are so prominent in the betterpreserved exemplars recounting this battle. By limiting myself to one portion of the scenes I hope that I have been able to highlight some of the aspects, not only of Egyptian artistic possibilities, but also of Egyptian accuracy.

All following figures after: EdUARD NaVILLE, Détails relevées dans les ruines de quelques temples égyptiens, Paris 1930.

103 LitTAuer-Crouwel, Wheeled Vehicles, 89-90.

${ }^{104}$ Epigraphic Survey, The Battle Reliefs of King Sety I, pl. 35. Others could be added. The number is clearly not two because of the brief lines added. We can see one additional line on the right side of the king and four strands at his back in pl. 34. Pl. 28 also shows the four strands.

${ }^{105}$ The Seti I example is also interesting in that we can see four reins were employed for the Hittite chariots: ibid., pl. 34.

${ }^{106}$ Naville Détails relevés, pl. VII (bottom, third chariot from left) = WresZINSKI, Atlas II, pl. 16 (bottom, third chariot from left). NAVILLE's drawing is in error.

${ }^{107}$ Logically, the charioteer must have had four reins, two for each horse. We must keep in mind that it is necessary to move the left reins and right reins together.
(How else is direction and motion indicated with more than one horse?) Nonetheless, the system was rather primitive:

1) There was no rein guard over the yoke pole. I.e., the left hand reins and the right hand reins do not appear to have been well coordinated as in later times. A rein guard keeps the reins associated with both sides under control because the reins then come together and cannot fall down and so get caught in the horses' feet.

2) There is no evidence that the left hand reins and the right hand reins came together to form one cord of leather. This method is employed instead of a rein guard. Usually, the two (or more) right hand side reins as well as the left are tied (or braided) together to form one thick cord that the charioteer holds. 


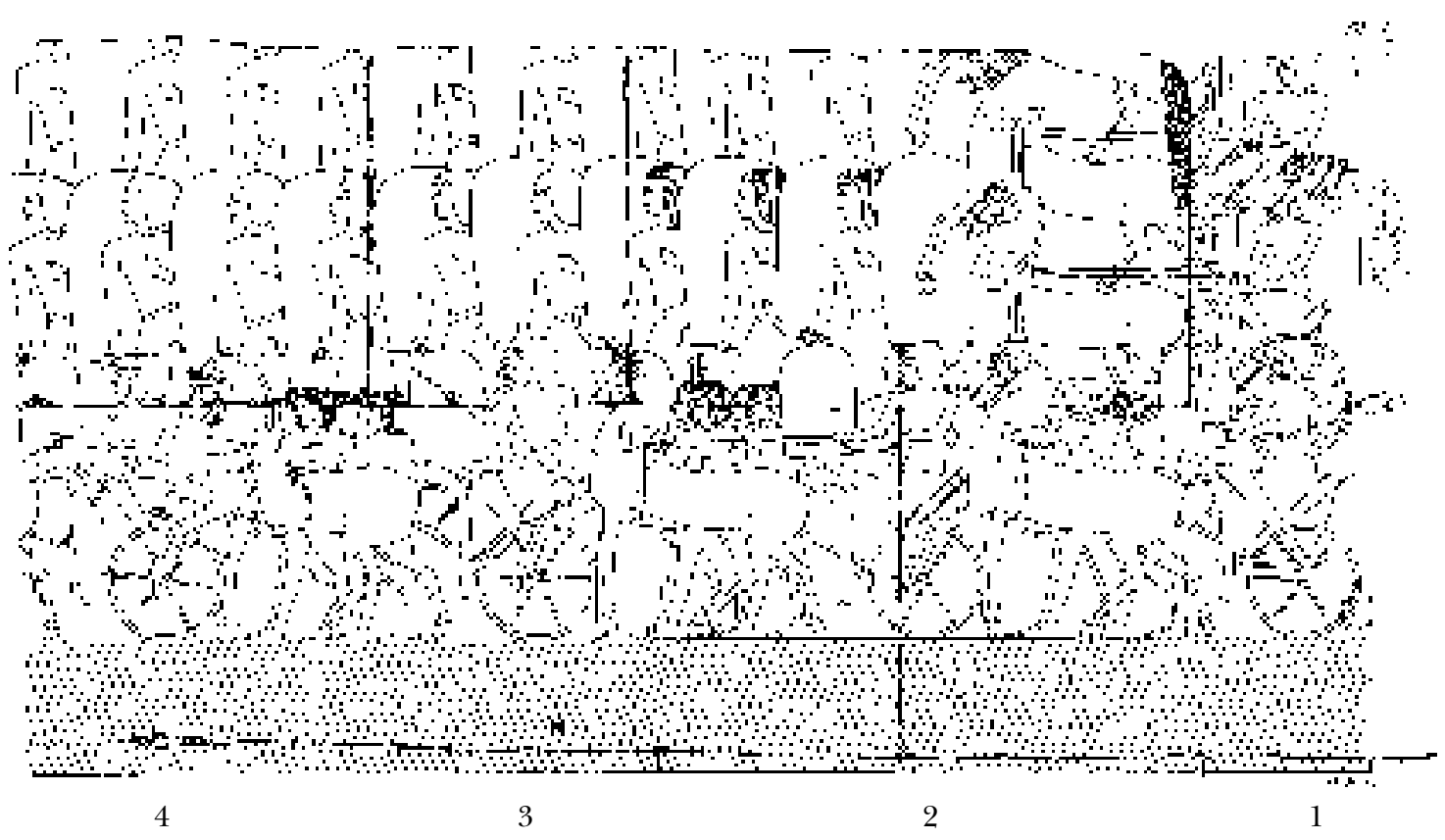

Fig. 1 Egyptian chariots

(after E. NAVILLE, Détails relevées dans les ruines de quelques temples égyptiens, Paris 1930, pl. V)

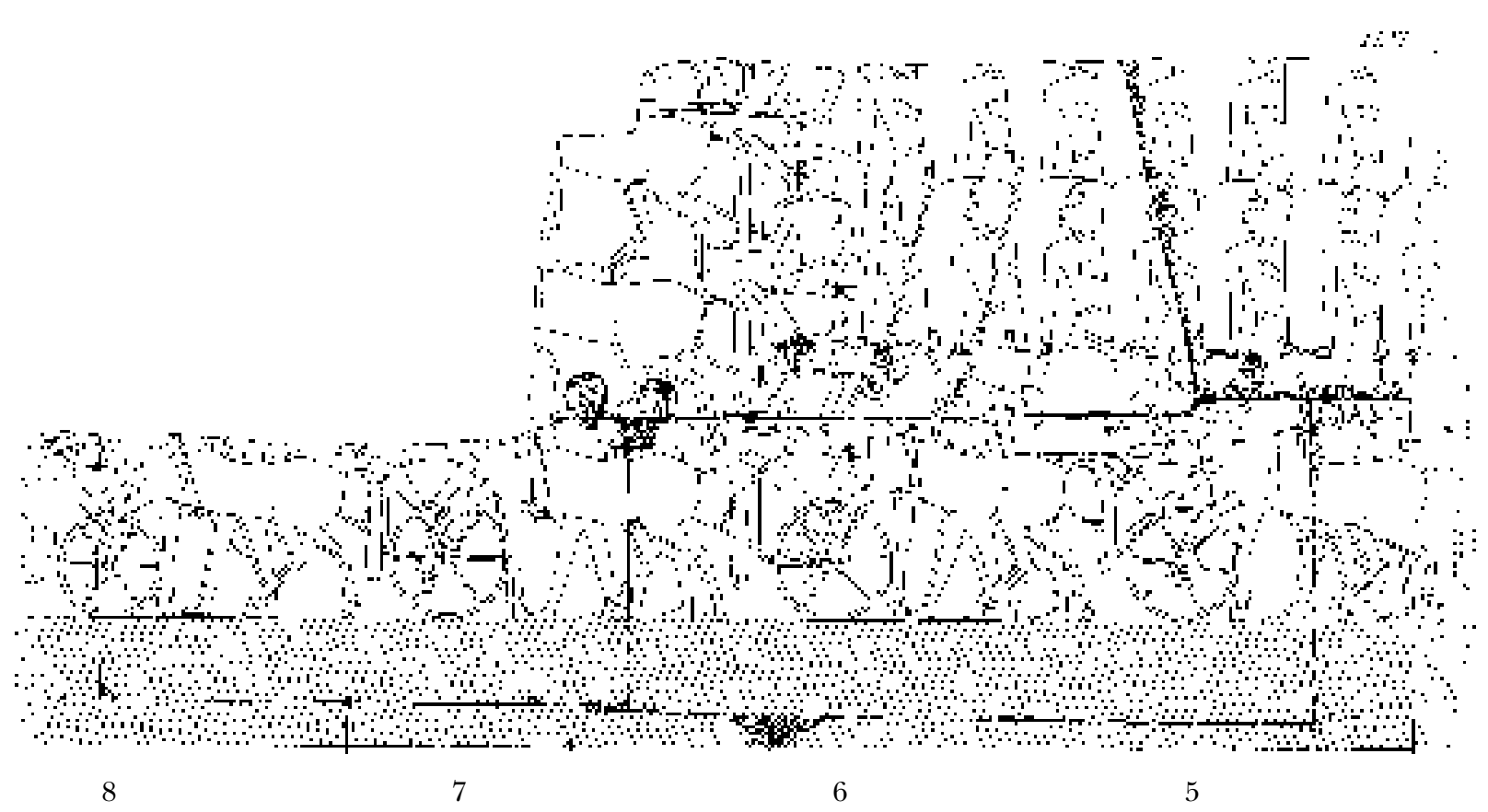

Fig. 2 Egyptian chariots

(after E. Naville, Détails relevées dans les ruines de quelques temples égyptiens, Paris 1930, pl. VI) 


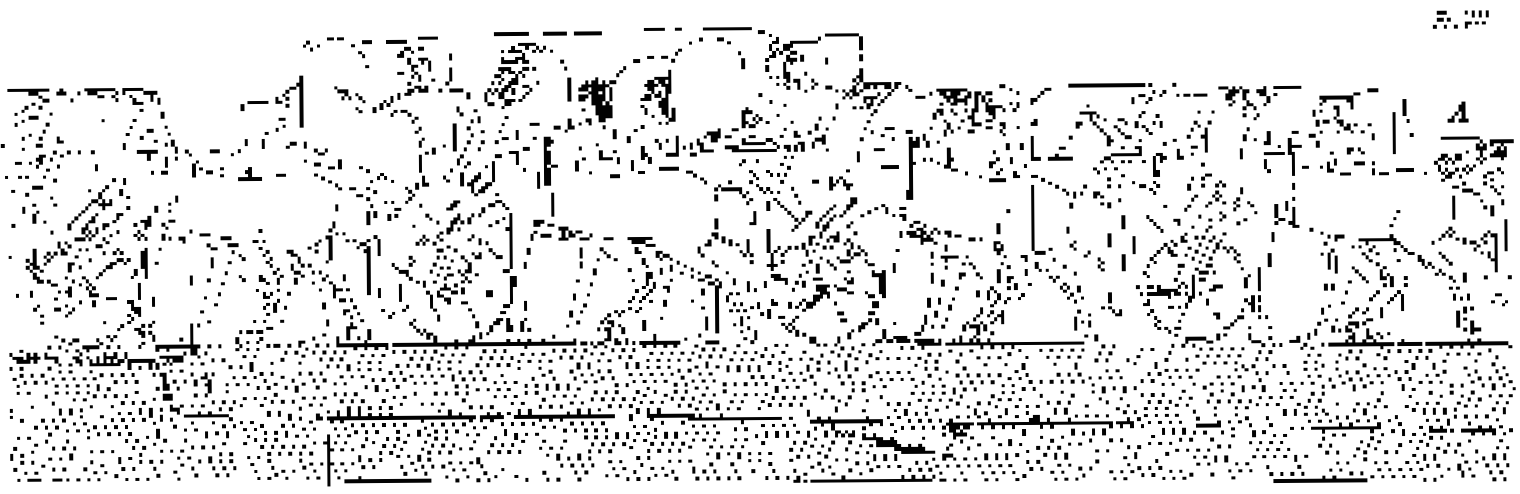

12

11

10

9

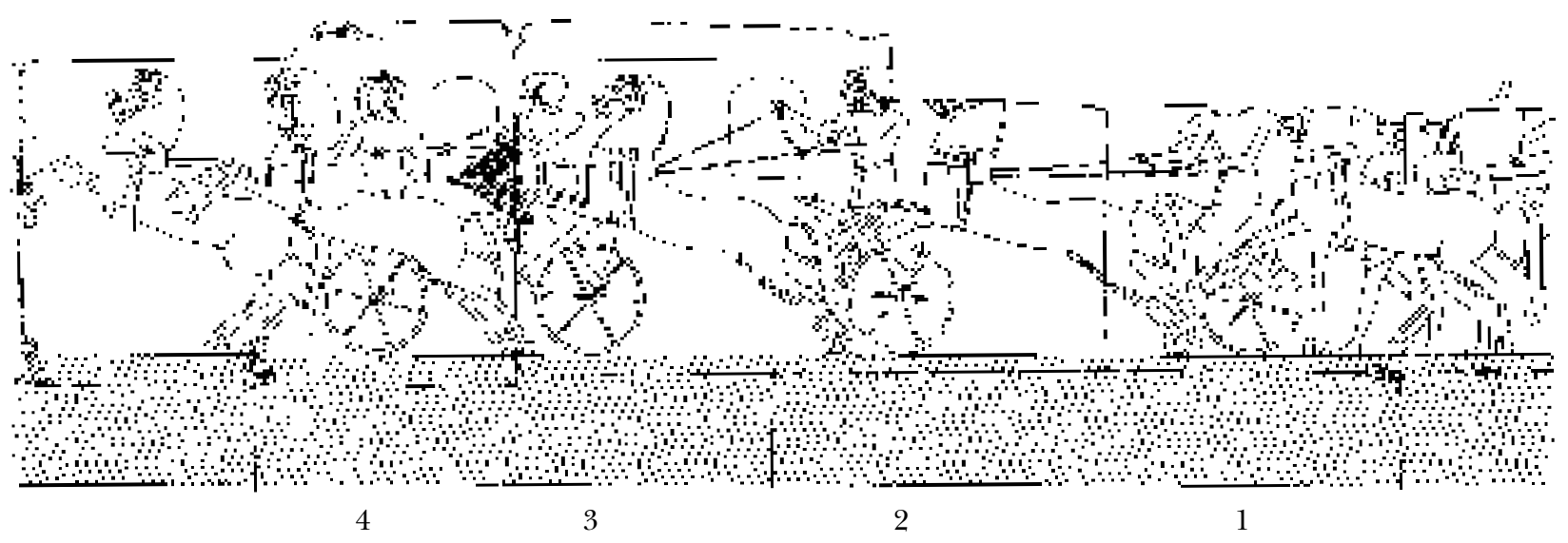

Fig. 3 Egyptian chariots

(after E. Naville, Détails relevées dans les ruines de quelques temples égyptiens, Paris 1930, pl. VII)

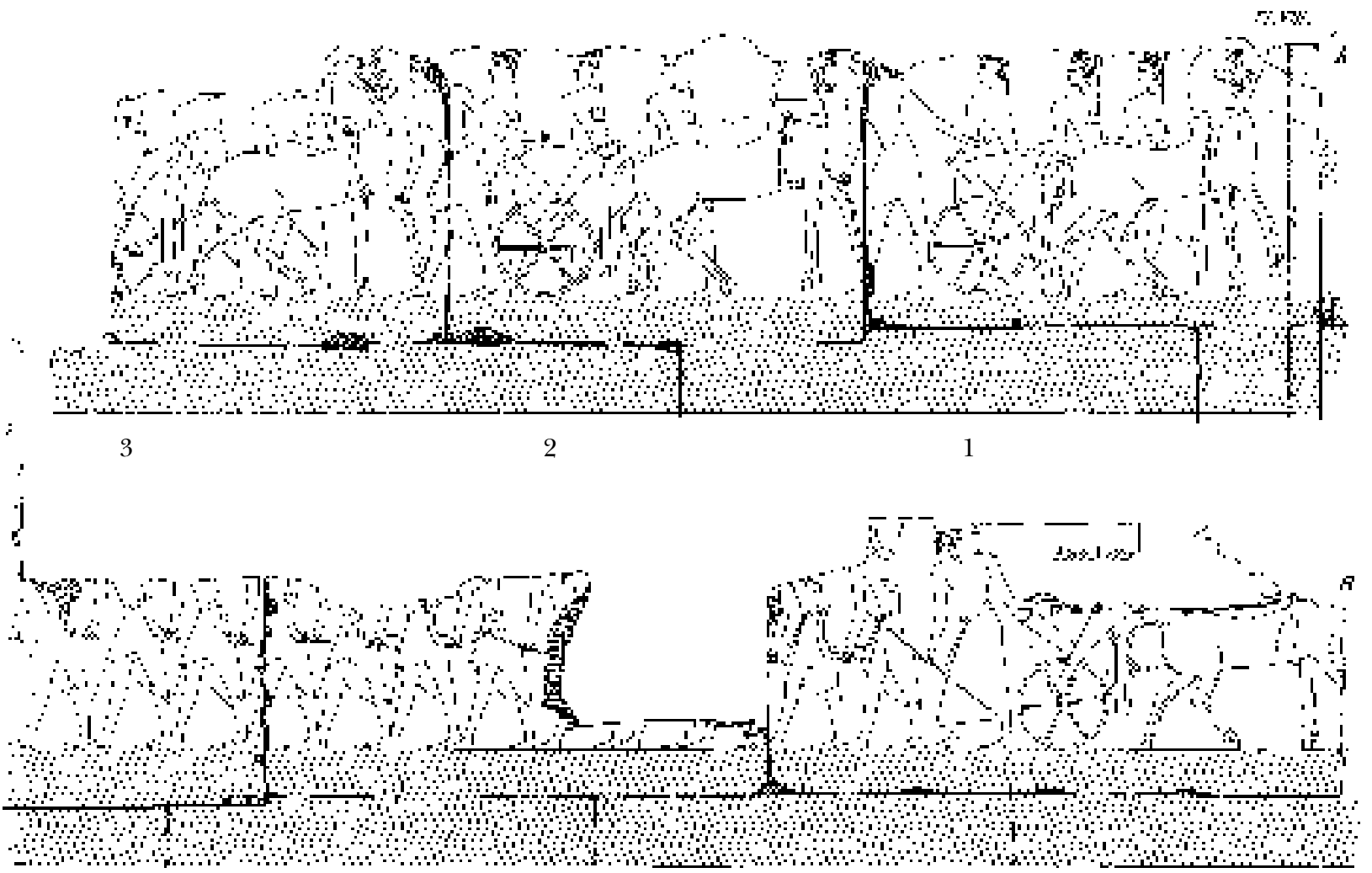

4

Fig. 4 Egyptian chariots

(after E. NAVILLE, Détails relevées dans les ruines de quelques temples égyptiens, Paris 1930, pl. VIII) 


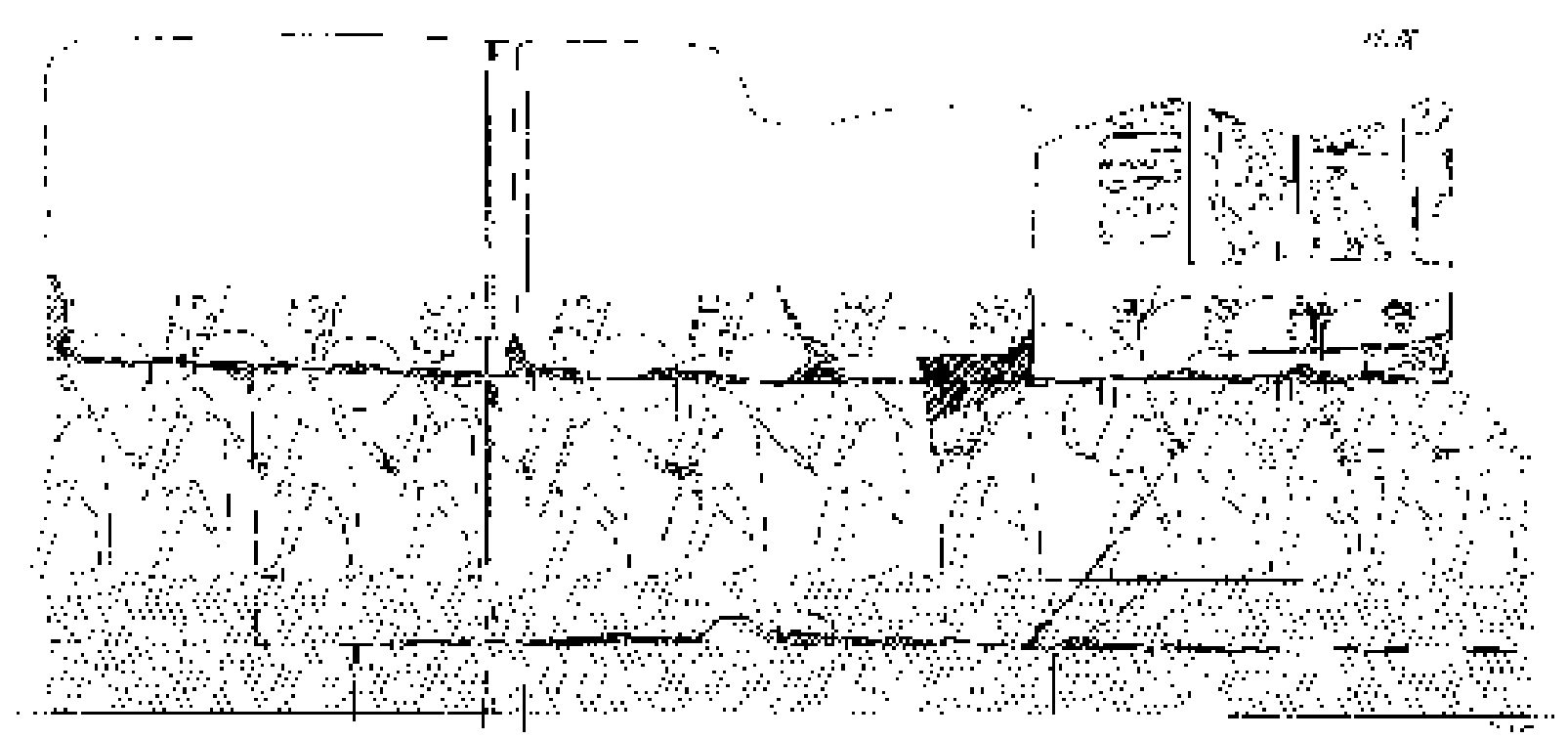

Fig. 5 Shardan troops

(after E. Naville, Détails relevées dans les ruines de quelques temples égyptiens, Paris 1930, pl. XI)

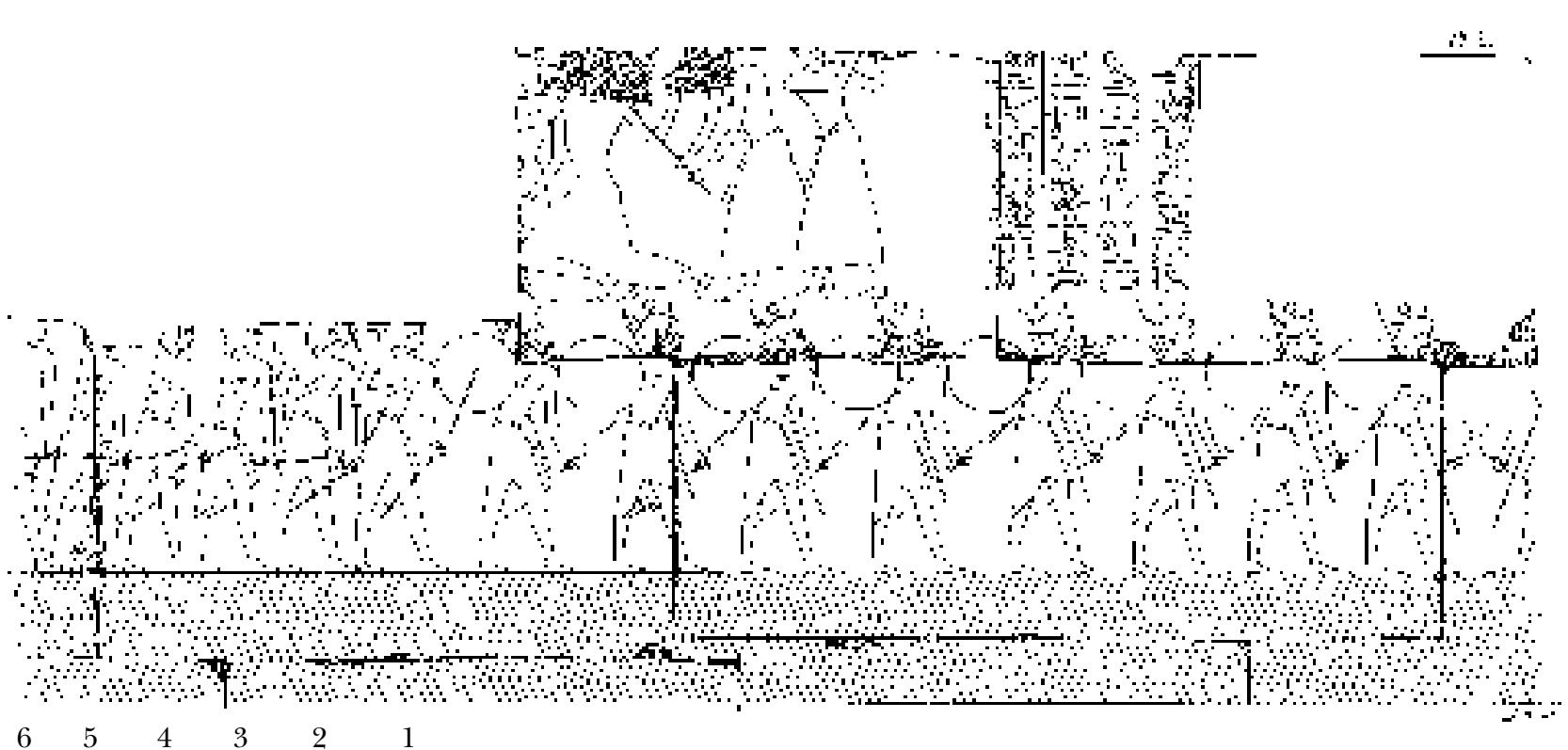

Fig. 6 Shardan troops

(after E. Naville, Détails relevées dans les ruines de quelques temples égyptiens, Paris 1930, pl. X) 

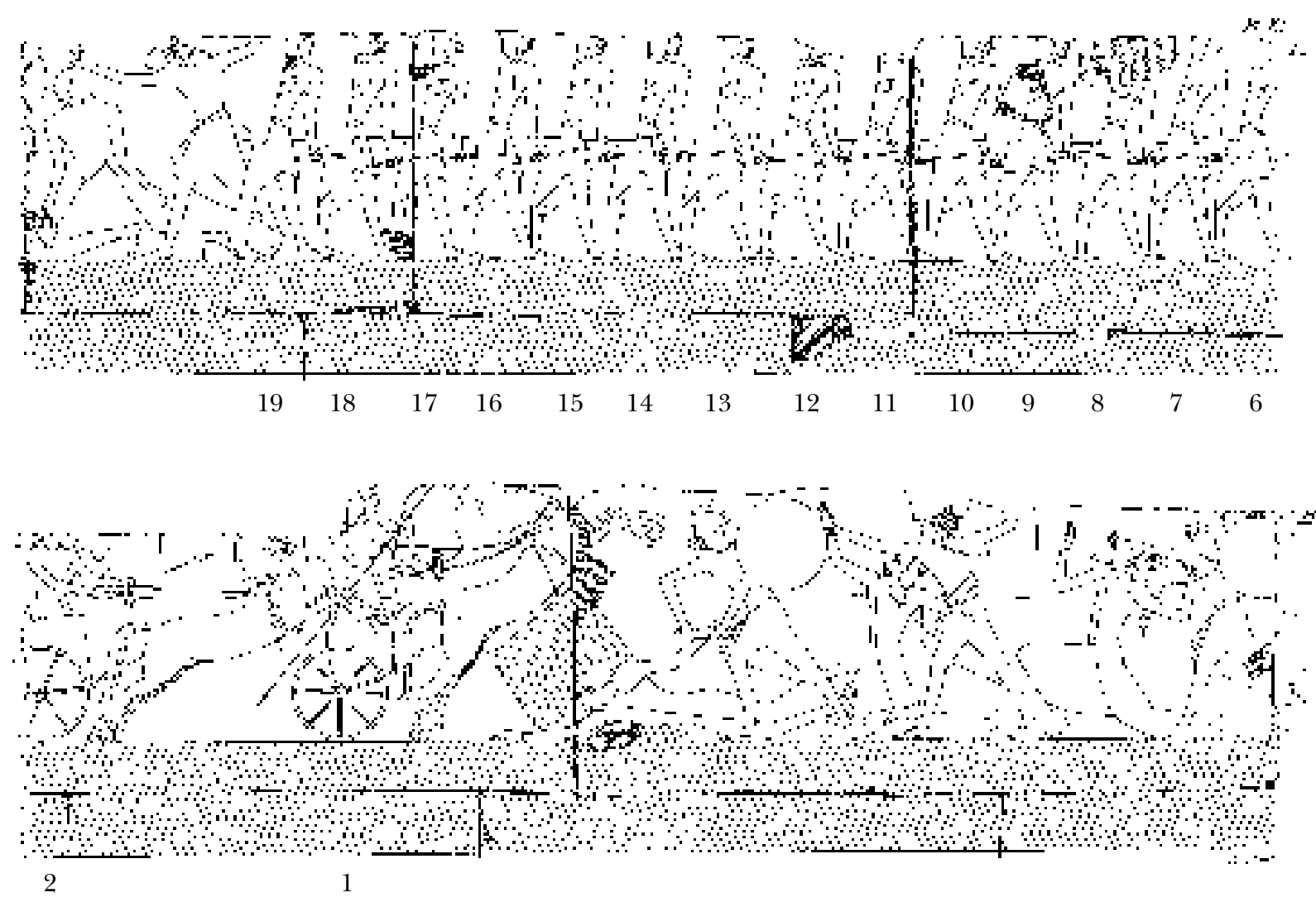

Fig. 7 Egyptian troops / enemy chariots

(after E. NAVILLE, Détails relevées dans les ruines de quelques temples égyptiens, Paris 1930, pl. XI)
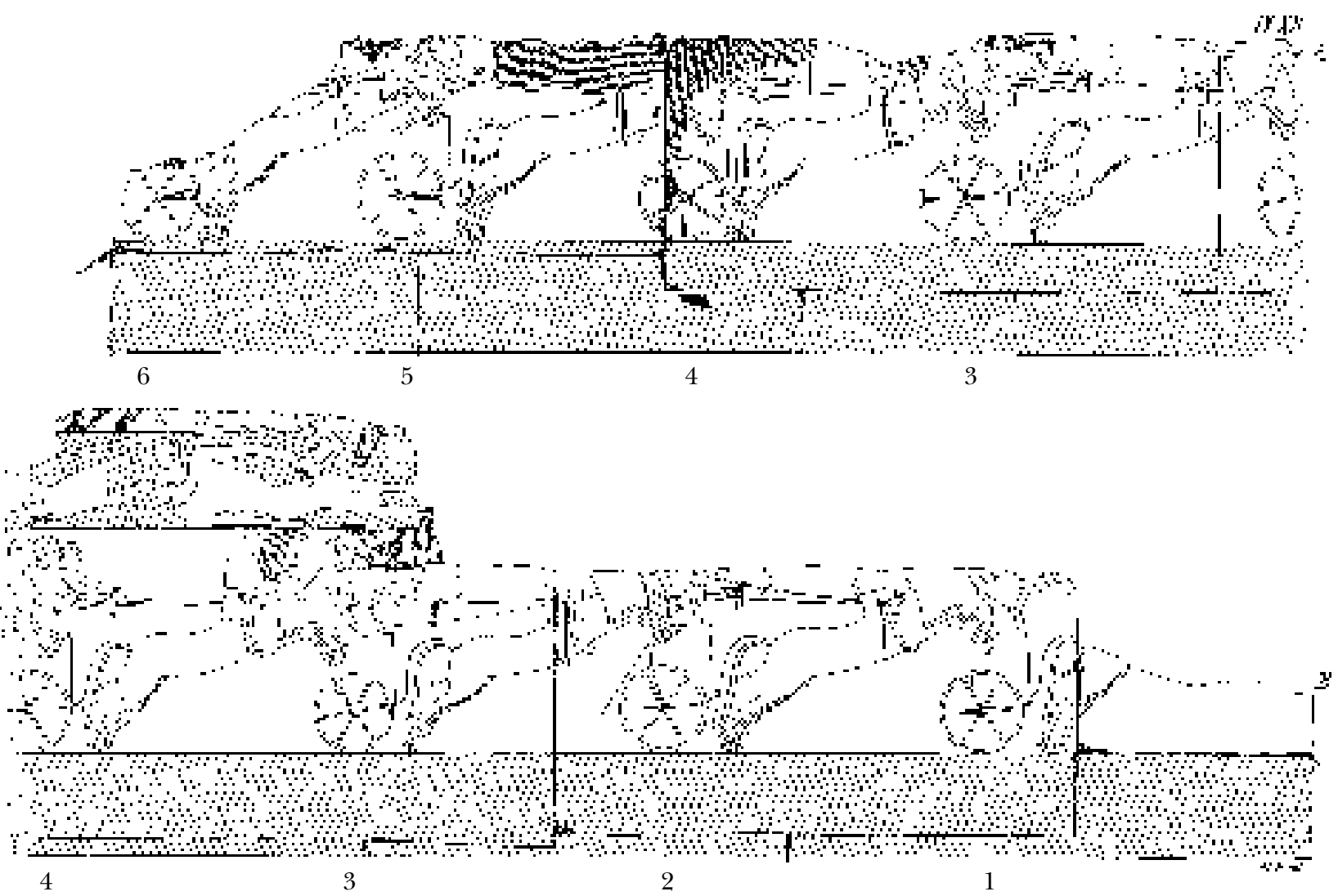

Fig. 8 Enemy chariots

(after E. NaviLLE, Détails relevées dans les ruines de quelques temples égyptiens, Paris 1930, pl. XII) 

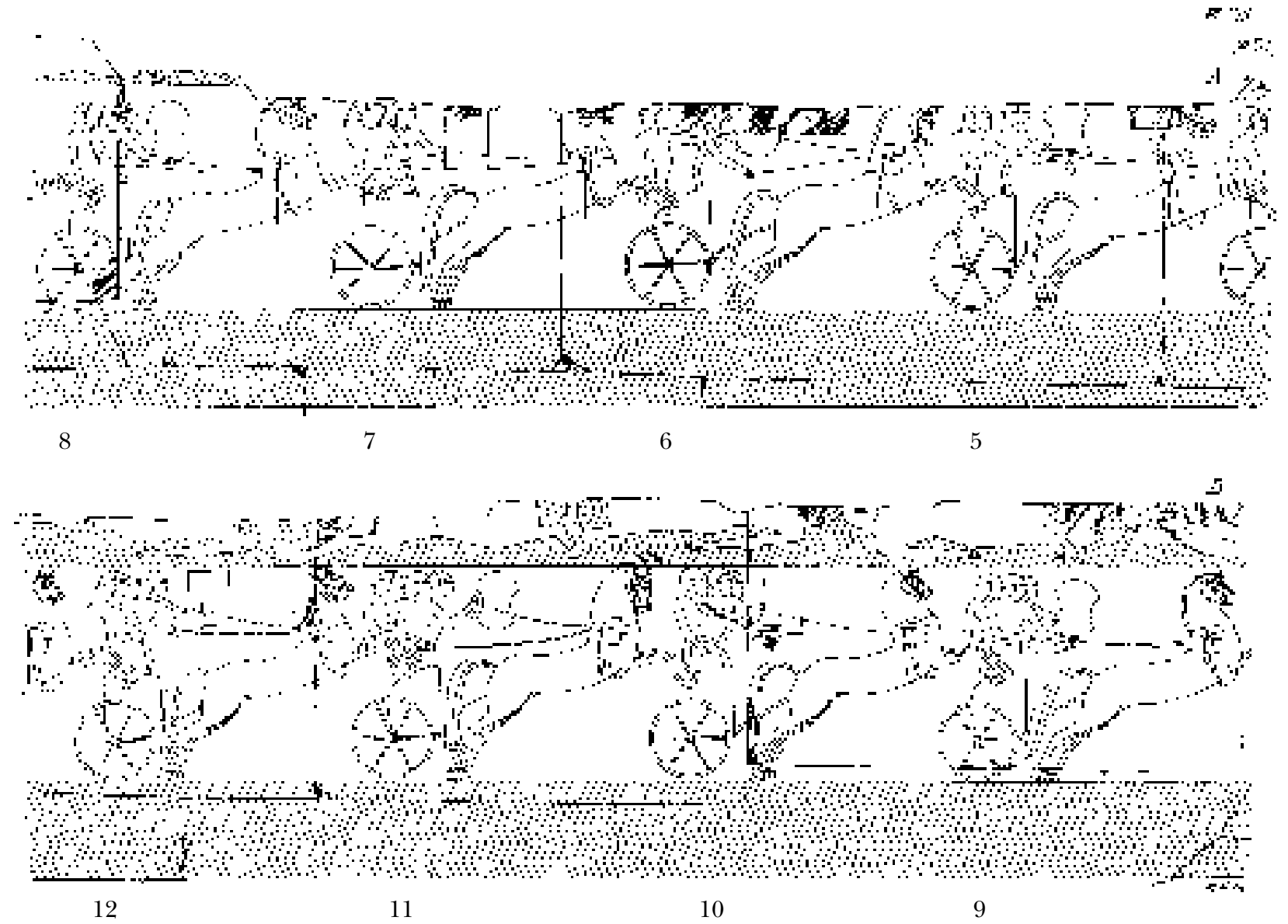

Fig. 9 Enemy chariots

(after E. NAVILLE, Détails relevées dans les ruines de quelques temples égyptiens, Paris 1930, pl. XIII)

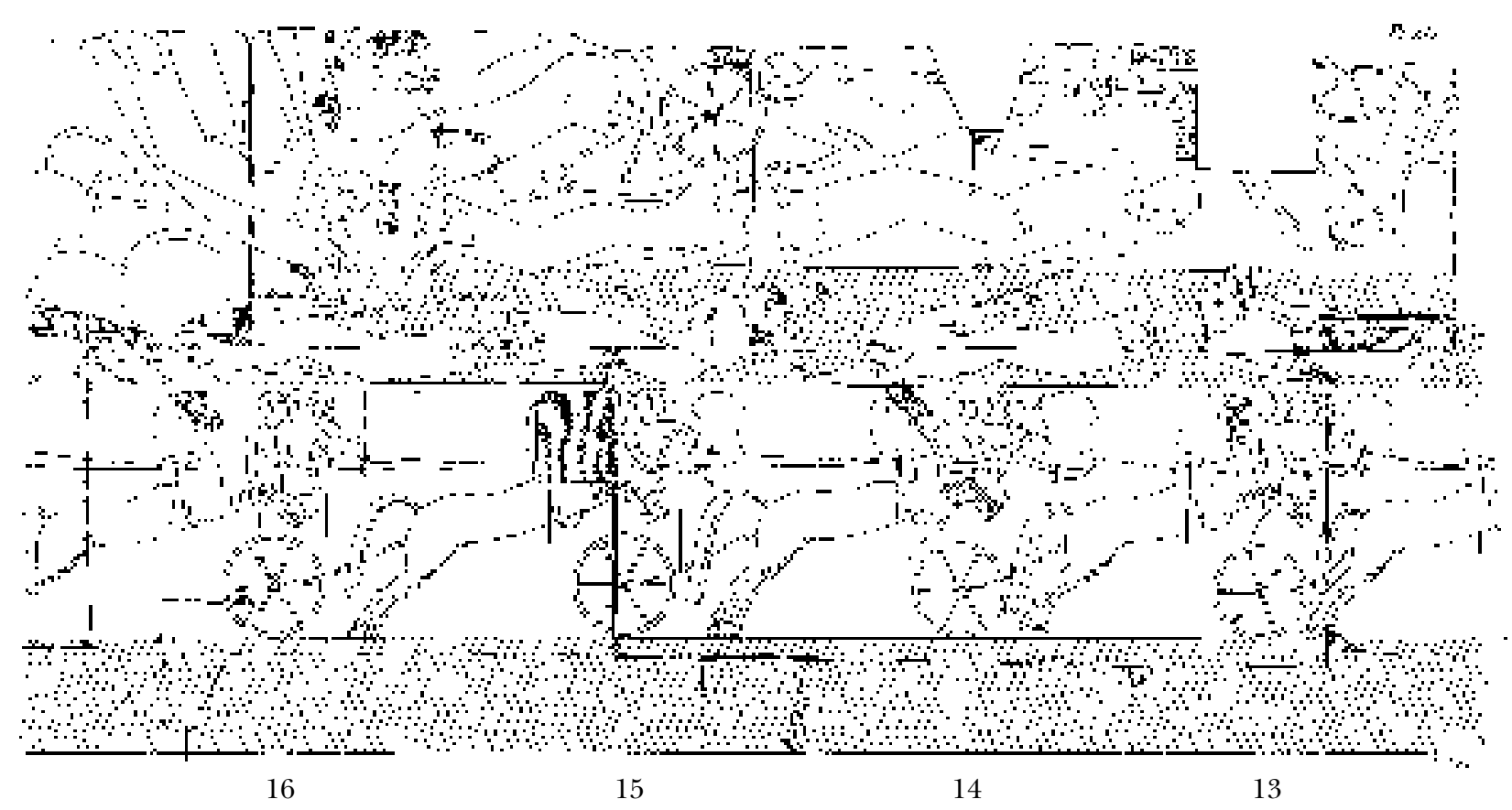

Fig. 10 Enemy chariots

(after E. NAVILLE, Détails relevées dans les ruines de quelques temples égyptiens, Paris 1930, pl. XIV) 


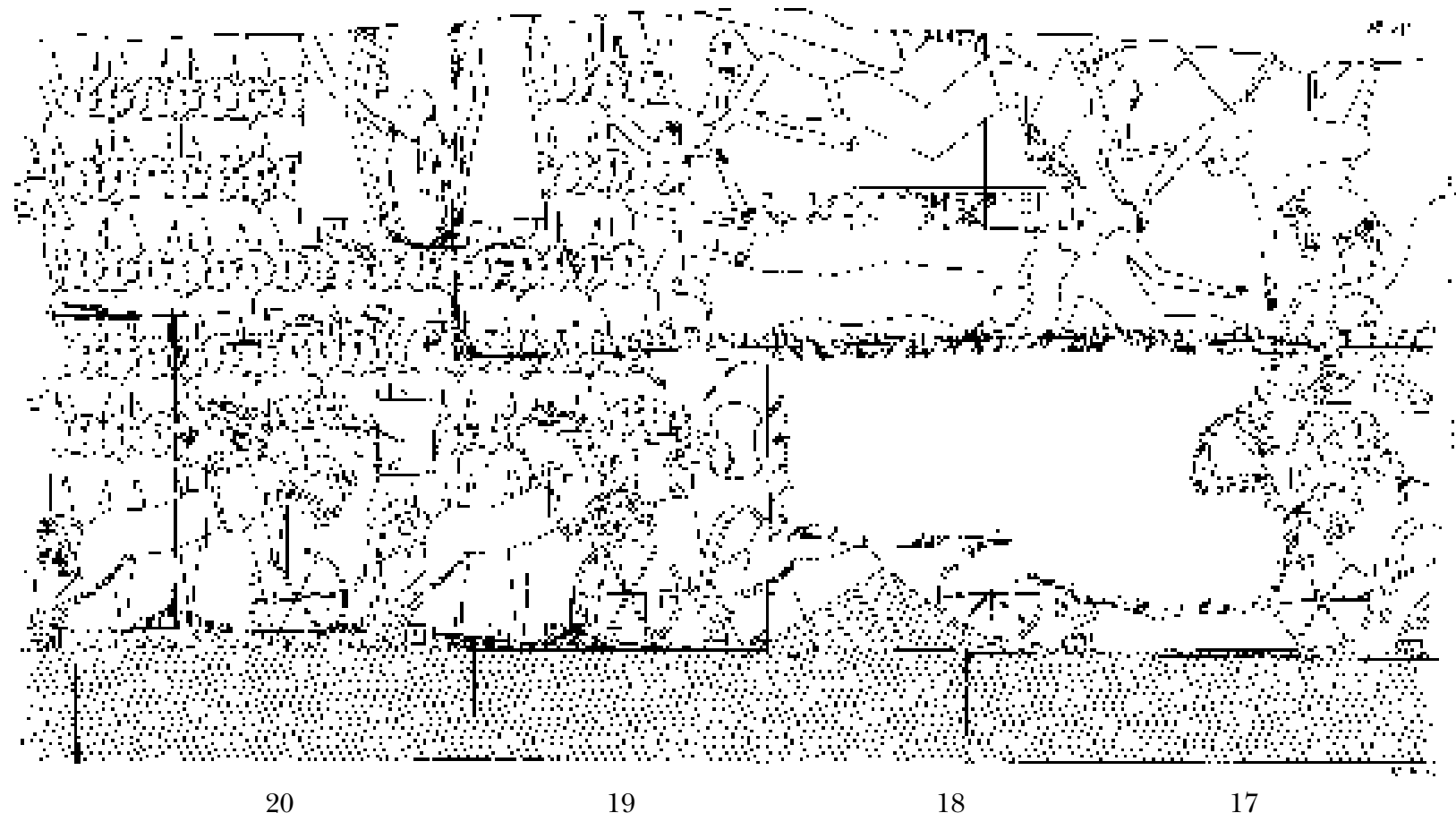

Fig. 11 Enemy chariots

(after E. NAVILLE, Détails relevées dans les ruines de quelques temples égyptiens, Paris 1930, pl. XV)

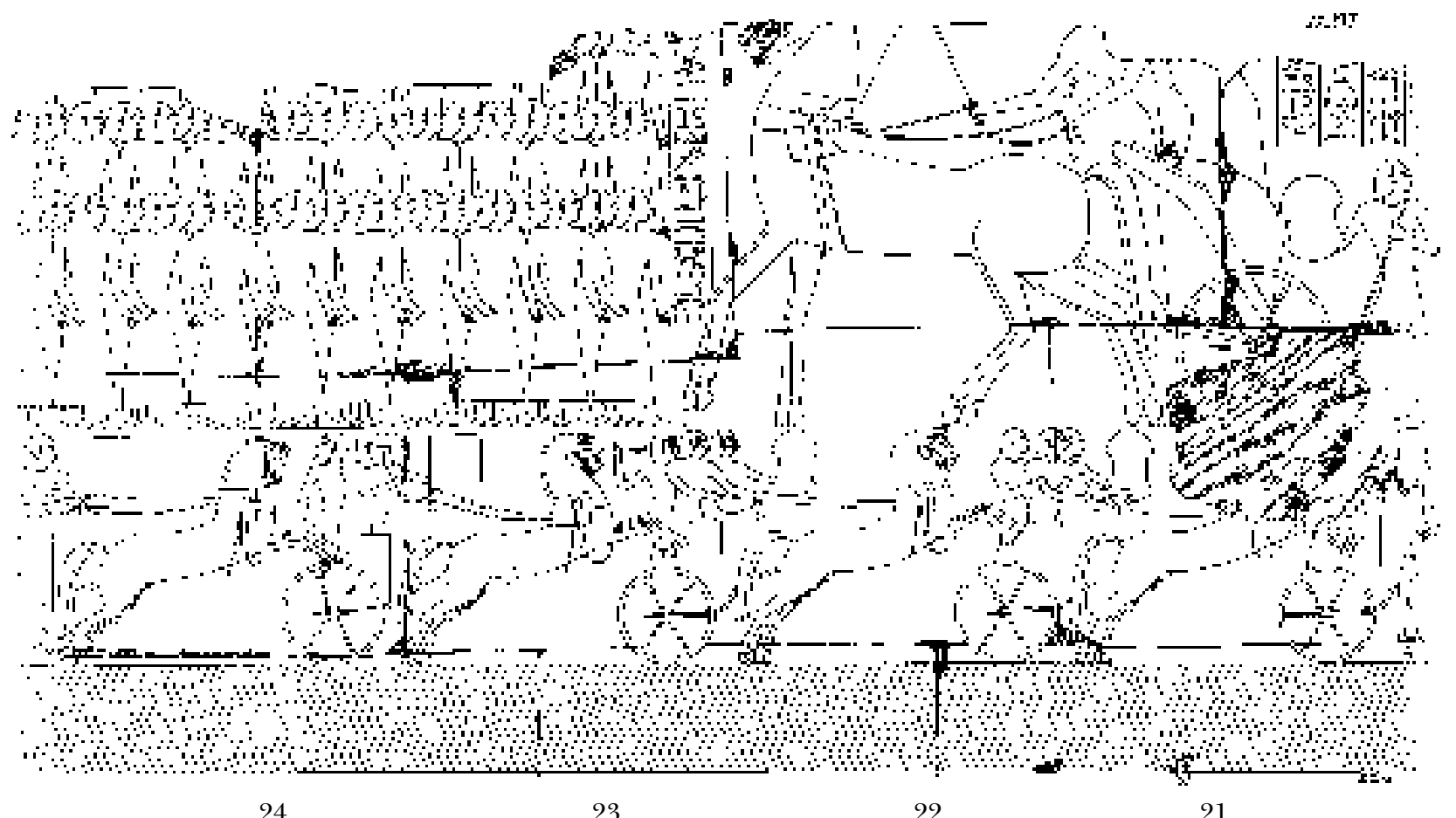

Fig. 12 Enemy chariots

(after E. NaVILLE, Détails relevées dans les ruines de quelques temples égyptiens, Paris 1930, pl. XVI) 


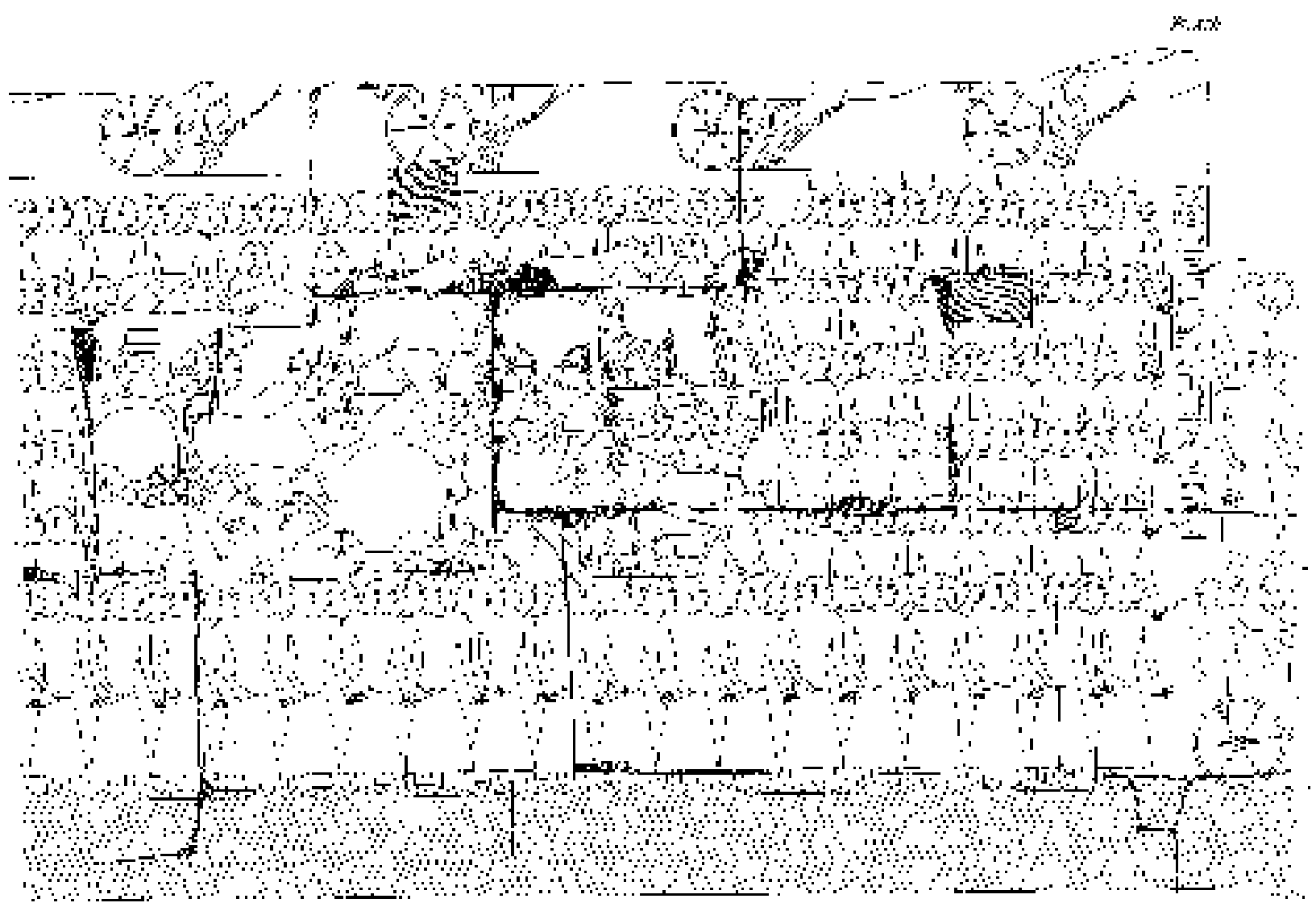

Fig. 13 Enemy troops

(after E. NAVILLE, Détails relevées dans les ruines de quelques temples égyptiens, Paris 1930, pl. XVII)

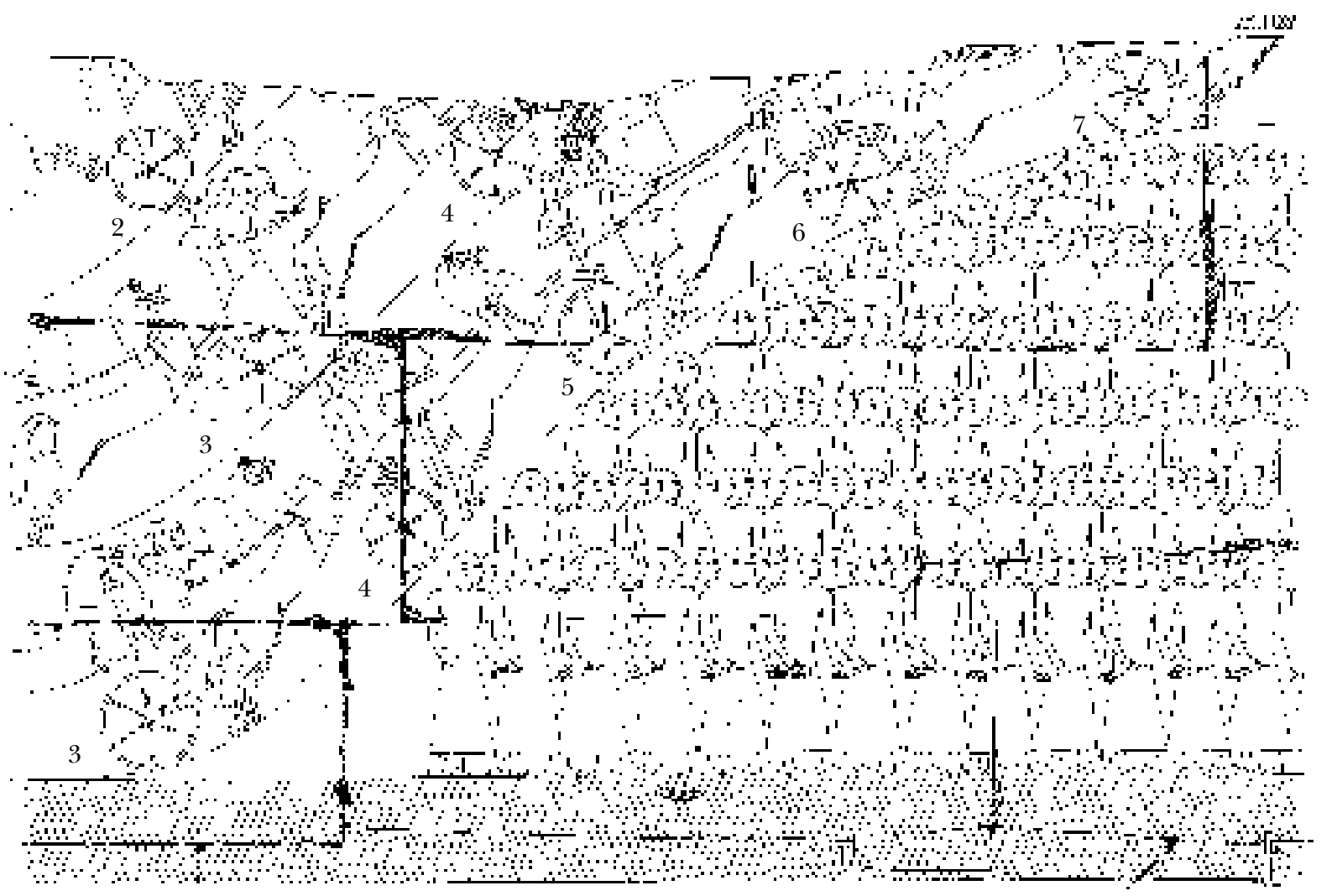

Fig. 14 Enemy chariots

(after E. NAVILLE, Détails relevées dans les ruines de quelques temples égyptiens, Paris 1930, pl. XVIII) 


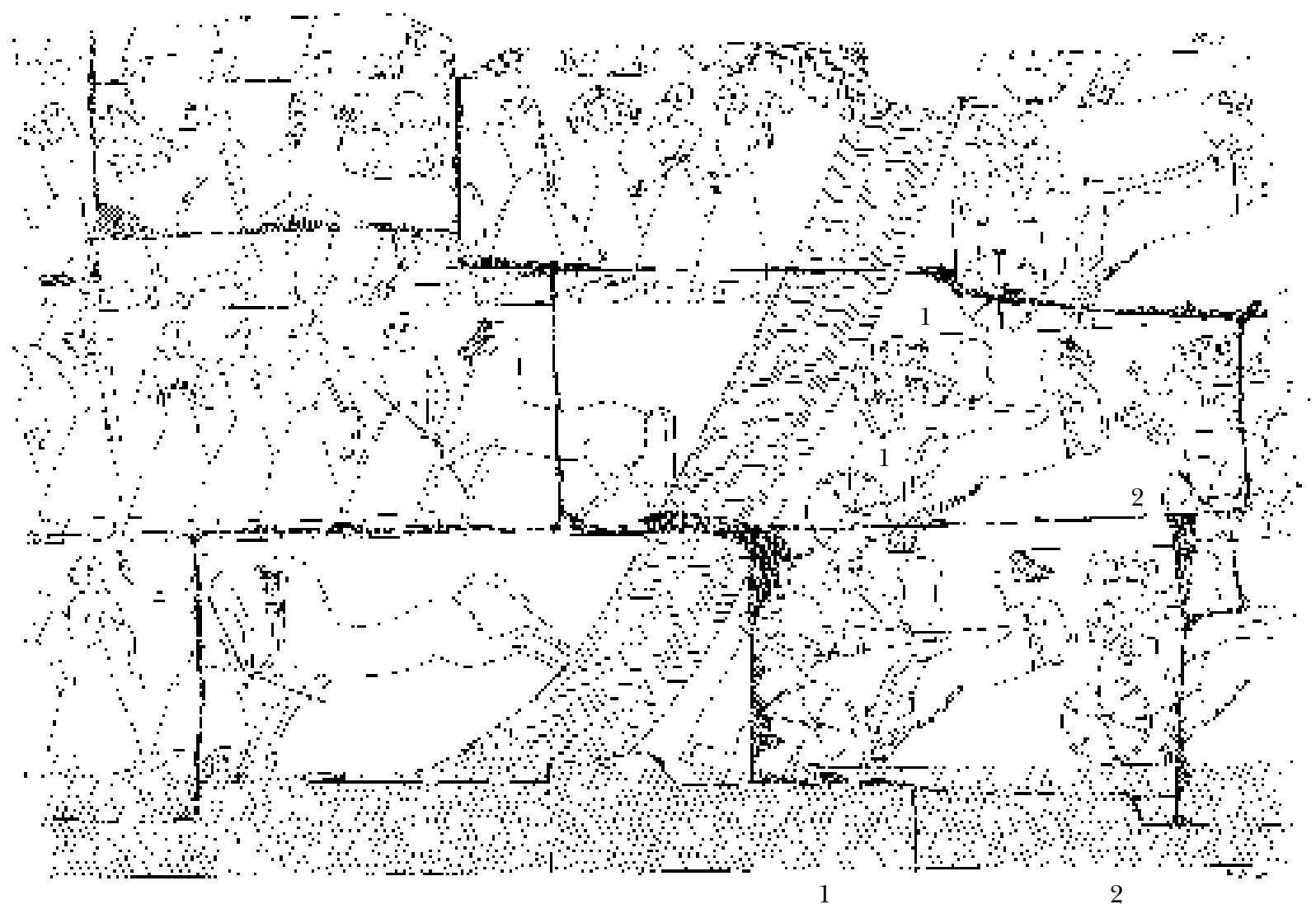

Fig. 15 Enemy chariots

(after E. NAVILLE, Détails relevées dans les ruines de quelques temples égyptiens, Paris 1930, pl. XIX) 